\title{
Multiple Prediction Of Research Productivity: H-Index
}

\author{
Peter James Kpolovie \\ Room 216, Education Building, Department of Psychology, \\ G. \& C., Faculty of Education, University of Port Harcourt, \\ East-West Road, P.M.B. 5323, Port Harcourt, Nigeria.
}

\begin{abstract}
Research Productivity, h-index, of faculty is predicted on their job-satisfaction, persistence, optimism, self-discipline, motivation, and procrastination. Never has been a better answer than $\boldsymbol{H}$-Index in the history of science to the question of how to quantify the cumulative productivity, accomplishments, impact, and relevance of a researcher's scientific work. Multiple Prediction design of correlational research method was adopted in the investigation. Faculty in natural sciences in universities around the world constituted the population. A multistage random sample of $\mathbf{1 8 0}$ faculty, $\mathbf{3 0}$ from each continent 7 or 8 from each of 24 universities, and 4 universities from each of 6 continents made the sample. Results showed statistically significant 21 correlation coefficients among the seven variables. The six independent variables taken together, significantly predicted research productivity $\left[F(6,173)=72.379, p<.01, R^{2}=.715\right]$. Each of persistence, optimism, self-discipline, and procrastination unilaterally predicted research productivity significantly. Neither job-satisfaction nor motivation singlehandedly predicted research productivity. Multiple regression equation was created for the prediction of research productivity from the six independent variables. Predicted values and residuals for each participant were tabulated.
\end{abstract}

Keywords: Research productivity; H-index; Multiple prediction; Research productivity hindex; Procrastination; Self-discipline; Persistence; Optimism; Motivation; Job-satisfaction; Continents in the world; Faculty; Correlational research method.

\section{INTRODUCTION}

There has never been a better answer than $\boldsymbol{H}$-Index in the history of science to the question of how to quantify the cumulative impact, relevance, and productivity of a researcher's scientific work. Research productivity comparison has fast become the best way for recognition and celebration of scientists and their contributions. Research rules the world. Radical scientific and technological changes are dependent on research. A number of factors may be associated with and perhaps responsible for the productivity of scientists that are yet to be investigated holistically. Therefore, the magnitude to which job-satisfaction, persistence, optimism, selfdiscipline, motivation and procrastination individually and collectively predict research productivity are examined in this study.

The $\boldsymbol{h}$-index is a metric that uses a single number to best measure a scientist's professional productivity as depicted by how many of the scientist's publications that have been cited up to $\boldsymbol{k}$ times by international publications of other scientists. The h-index is the best numerical representation of the impact and productivity of a researcher/scientist, strictly based on the researcher's publications and patents, rather than the impact factor of the journals in which the papers were published. Journal impact factor, calculated as the average number of citations per article in the journal within the previous two years (Google Scholar, 2017; Marnett, 2017), is indeed a measure of the journal; and not of the scientists or researchers whose papers populated the journal. Journals are correctly ranked in terms of their impact. A journal that 
published 100 articles, only 10 of the articles might have been cited severally for the journal to qualify as a high impact journal; so it cannot be right to attribute the glory of the journal to any of the redundant (not cited) papers in the journal. It is only the measure of the individual scientists, and definitely not that of the journal, that can correctly reflect the productivity of a scientist. Rather than measuring and ranking journals based on journal impact, $\mathbf{h}$-index is a valid and reliable index on which the relative importance, productivity, or accomplishments of scientists are established and ranked (Hirsch, 2005; 2007). The h-index depicts the number of highly impactful research publications of a scientist, regardless of the journals in which they were published (Becker Guides, 2016). The more the highly impactful papers of a scientist, the greater his h-index (Scibendi.com 2018). "H-Index is a numerical indicator of how productive and influential a researcher is. It was invented by Jorge Hirsch in 2005, a physicist at the University of California" (Spicer, 2015).

Overall, the h-index is indeed a much better measure of research or scientific productivity than other metrics that indicate scientific output (Harzing, 2017). H-index is a measure that best reveals the extent to which a scientist is productively publishing or unproductively perishing. "Publish or perish" has over the decades been coined to depict the pressure that propels the academia to ceaselessly publish scientific papers for the sustenance and furtherance of the chosen academic career. While a perishing academia has little or no h-index, a publishing scientist has a large h-index (Kpolovie, 2013). Academic talent is demonstrated by a scholar with regular publications of his several research works. Such talent attracts citations and international attention to a scholar and his affiliated institution. It is the best possible bibliometric indicator (NIH Library, 2018) of a scholar's impact and influence in his chosen profession. Scientists with low h-index may need to do more research, and publish more (Mattmight, 2015; Pacheco-Vega, 2013).

The "Publish or Perish" is a bibliometric software for the retrieval of raw citations, via Google Scholar, and the analyses in order to present 12 types of output for each scientist. The output types are total number of published papers, total number of citations, average citations per paper, citations per author, number of citations per year, Hirsch's h-index, g-index, contemporary h-index, number of citations per author's career age, dual variations of hindices, number of authors per article, and number of papers per author (Harzing, 2017 \& 2010).

Only the total number of papers published and the total number of citations the publications received are required for the determination of a researcher's h-index (Hirsch, 2005; 2007; Spicer, 2015). This is simply because h-index is a researcher's k publications that have each been cited at least $\mathrm{k}$ times by other publications that are readily available online (Library Guides, 2017). If the total number of publications by scientist A is 12 , the total citations made of his publications is 32 , only 4 of his publications have each been cited up to 4 times; the hindex of scientist $A$ is 4 . If out of scientist B's 100 publications and 300 citations, 15 of the publications have each been cited at least 15 times, then scientist B has $15 \mathrm{~h}$-index. If scientist $Y$ has made a total of 70 publications that have attracted 500 citations; of which 20 of the publications have each been cited not less than 20 times, the h-index of scientist $Y$ is 20 . But if scientist $\mathrm{Z}$ has a total of 70 publications and a total of 500 citations and only 10 of the publications have each been cited up to 10 times, Z's h-index is 10 . The publications, citations and h-index of scientist A are diagrammatically illustrated in Figure 1. 


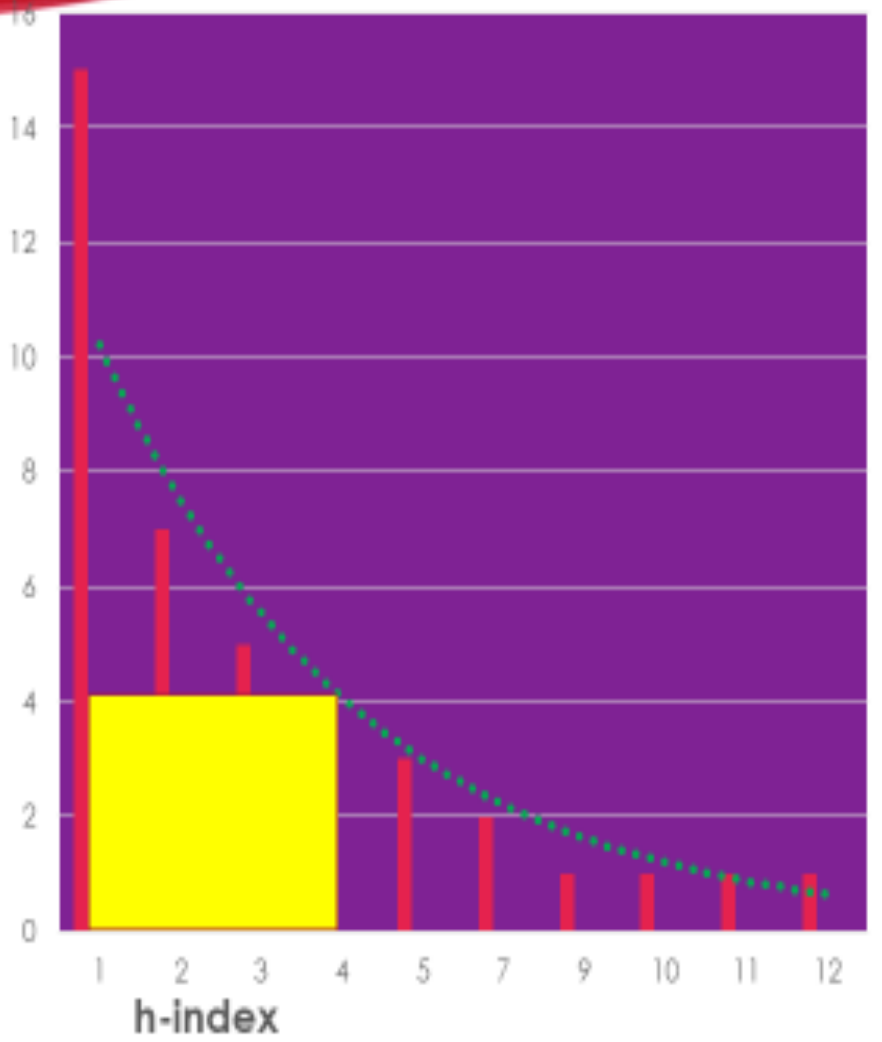

Figure 1: H-index of scientist A.

Let me illustrate the measurement of h-index with two other examples in case, it is not yet clearly painted. If $\mathrm{k}$ stands for each published paper of a scientist; to find his h-index, first order the $\mathrm{k}$ from the most cited to the least cited. The h-index is the rank order position at which $\mathrm{k}$ is greater than or equal to the k's position. For instance, if a scientist's k1, k2, k3, k4, $\mathrm{k} 5, \mathrm{k} 6, \mathrm{k} 7, \mathrm{k} 8, \mathrm{k} 9$, and $\mathrm{k} 10$ have each received the following citations respectively, 30, 24,20 , $15,11,9,7,5,3$, and 1 ; his research productivity is 7 . Then if another scientist has ten ks that have each received the following citations respectively, 80, 40, 35, 20,10, 4, 3, 2, 2, and 1; his hindex is 5 . In the first case, k7 has received 7 citations, and below it, k8 has been cited less than 8 times, so the h-index cannot be more or less than 7. In the second case, k5 has been cited 10 times that is greater than 5, and bellow it, k6 has been cited only 4 times that is less than 6 times; hence the h-index cannot be more or less than 5 .

Characteristics of $\mathbf{h}$-index are as follows:

1. Most valid and reliable measure of research productivity.

2. Reliance on citations received by the scientist's publications.

3. Immunity to a large number of poorly cited publications.

4. Immunity to a small number of exceptionally well-cited articles.

5. Immunity to the negative politics of journal citation impact.

6. Immunity to the negative politics of peer competitors' rejection of a rather very good paper.

7. Best comparison of scientists in similar professions and career durations.

8. Accords even regard to every citation made.

9. Encouragement of collaborative research.

10. Allows for comparison of only works published within a given period of five, ten, fifteen, etc. years.

11. Increasing difficulty in grading to ensure that every one unit increment is indeed a much more remarkable achievement. 
12. Superiority in the prediction of future scientific accomplishments over other measures of research productivity such as citations per paper, total citations, total papers, journal impact factor, and students' academic performance (Hirsch, 2007).

13. Guarantees transparency in the evaluation of a researcher's productivity by anyone who cares merely by typing the researcher's name into Google Scholar search engine.

14. Has become a necessary part of the process of evaluating job applicants for academic positions, promotions, and for awarding of research grants.

15. Boosts scholar's honesty, accuracy, accountability, reputation, and international research dissemination.

16. Simultaneously measures the quality and quantity of a scientist's output.

17. Favours publication of a continuous or sustained stream of papers that have lasting and above average impact.

18. Easily amenable to other indices like g-index, e-index and m-index for enhanced accuracy.

19. M-index is a scientist's h-index divided by the number of years since his first publication for better comparison of early stage and late stage scientists by averaging periods of low and high productivity years across each of the scientists' career (Hirsch, 2007).

20. G-index is the square $\left(\mathrm{g}^{2}\right)$ of exceptionally well-cited articles above the h-index (Egghe, 2006).

21. E-index is the square root of the sum of excess citations above and beyond the h-index (Zhang, 2009).

In his study, Kern (2011) presented a model for evaluating components of academic research productivity sources. The sources were made up of six factors - i) funding; ii) investigator quality; iii) efficiency of the research institution; iv) research mix of novelty, incremental advancement, and confirmatory studies; v) analytic accuracy; and vi) passion. The model posits that output divided by units of reference equals productivity. Results showed that these factors interact to produce a pattern of influences for optimisation of academic research productivity. Kern postulated the model out of his belief that a metric for measuring productivity should be difficult because simple metrics can easily become "systematically influenced by learner behaviours." Output in the model (output divided by units of reference = productivity) refers to the number of publications, patents, and/or clinical trials in a time period. However, the model seems to be ambiguous because of its claim that "expressed output as a ratio, such as output per dollar, per nation, per institution, per investigator... they become measures of efficiency or productivity"; since efficacy is itself one of the units of reference.

Mueller, Gaus and Konradt (2016) investigated prediction of research productivity in international evaluation journals across countries from 2009 to 2013 with a sample of 65 countries that got reduced to 58, using cross-sectional survey research design, and a machine learning technologies that were rooted in "regression trees". They collected data for the criterion variable on the basis of only 10 journals that focus on aspects of evaluation research, practice, concepts, and methods. Their unit of research productivity measurement was the number of authors for each journal article and not even the number of articles published by the participants, nor the scholars' citation index, nor h-index. Thus, the Mueller, Gaus and Konradt (2016) predictive study of research productivity left so much to be done. They, however, found that research productivity is predictable across countries with their model; and that research productivity in the social sciences had the strongest effect $(48.9 \%)$, followed by economic prosperity (16.8\%), control of corruption (10.0\%), and age of evaluation society $(8.3 \%)$. They rightly suggested, in conclusion, that "further research should try to identify the causal mechanisms behind the correlational relations we found in our study." Hopefully, the current study will largely fill the identified knowledge gap by specifying some causal mechanisms. 
Only a very small fraction of universities in the world, about 0.05 or $5 \%$, value research productivity. Overwhelming preponderant universities worldwide, 0.95 or $95 \%$, out of the roughly 20,000 universities globally accord either too little or no regard at all to research productivity (Kpolovie, 2013). This accounts for why only about 1,000 of the existing 20,000 universities appear meaningfully in the renowned international rankings such as the QS World University Rankings (Quacquarelli Symonds) and Times Higher Education World University Rankings (THE) (Kpolovie \& Obilor, 2013). About 19,000 of the 20,000 world universities are still mere teaching institutions with extremely limited research mission. The $95 \%$ of world universities that are ordinary teaching institutions emphasize teaching and learning, without attention to improving their research productivity profile (Kpolovie \& Akpelu, 2017). These non-research productivity universities measure productivity in the academic system in terms of 'effective teaching' and a good understanding of what students learn, and are concerned primarily with ensuring that their students complete their studies (Altbach, 2015) usually at the undergraduate level. They tend to forget that there cannot be effective teaching without productive research (Kpolovie \& Awusaku, 2016). At best, they see and evaluate research productivity in terms of Journal Impact Factor that depicts how well a journal, not the author, is cited. In line with the founder and director of the Center for Science and Technology Studies at Leiden University in the Netherlands, Anthony van Raan; Noorden (2010) has asserted that "if there is one thing every bibliometrician agrees, it is that you should never use the journal impact factor to evaluate research performance for an article or for an individual - that is a mortal sin." Due to the lack of emphasis on research productivity, faculty in non-research universities tend not to accelerate certain vital personal qualities or habits that might profoundly influence their research and international publication endeavours (Kpolovie \& Onoshagbegbe, 2017; Kpolovie \& Awusaku, 2016).

Universities that are research-intensive concentrate on measuring academic productivity of staff in terms of the latter's research accomplishment, which is the core mission of a global university. It is on the basis of faculty's research accomplishments that universities are ranked universally. "Research productivity is easier to measure (validly and reliably) than other kinds of academic work" (Altbach, 2015). Global universities count publications that are available online, and have made impact by attracting substantial citations as indicated by h-index in major international databases such as the Web of Science, Science Citation Index, Google Scholar Citation Index (h-index in particular), Scopus, Publish or Perish, ISI Web of Knowledge, and the like for various professional disciplines. Faculty with high research productivity as measured by their citation index or h-index are not only recognised but are paid special bonuses that even double their salaries in research-intensive universities. Bibliometric analyses of research databases have shown that Nobel laureates have not only published five times the average number of papers, but their articles have also been cited 30 to 50 times more than the average of their counterparts (Altbach, 2015; Marnett, 2017). Thesis Whisperer (2016) indicated that effective organisation and management of tasks and activities tend to help faculty to become more productive. Use of software for tasks or activities management like Omnifocus2 and Asana have also been recommended for productivity enhancement.

Job-satisfaction and motivation might play an influential role in the prediction of faculties' research productivity. Some persons may work very hard and tirelessly in conducting research and dissemination of the outcome frequently simply as a function of the great satisfaction that they derive in continuous selfless research. This may increase their practical experience in knowledge discovery, development and exercise of high-level skills, active participation in socially worthwhile knowledge creation enterprise (Kpolovie, Ewansiha \& Esara, 2017). Some faculties may see their exceptional engagement in research as intrinsic motivation that is far more powerful than extrinsic or external rewards. For them, external motivation like increased 
salary, promotion, rank, prize or exemption from much teaching courses may soon reach the point of declining impact. Thus, motivation (intrinsic or extrinsic) might be adopted successfully or otherwise in improving faculty's long-term research accomplishments (Martin, 2009).

Attempts geared at improving research productivity by persons other than the individual researchers themselves tend to yield highly restricted success. Orthodox incentive systems are bound to produce two sides of the coin, positive results for a few and negative results for the majority. The positive results include spurring some faculty to become winners, grants receivers, having promotions, and recognitions. The adverse outcome might be that a vast majority of the faculty may consider themselves as losers, suffer a feeling of humiliation for not being able to measure up to the highly research productive colleagues, and the consequent refusal to try. When rewarding the few with high research accomplishments ignite shame feeling and debilitating emotion in the university, the productivity of the majority might tend to become blocked.

Optimism may influence research productivity. Optimistic individuals expect success in everything and may be more likely to achieve success than pessimistic people in scholarly accomplishments (Academic Voice, 2017). In fact, optimism could be considered as a type of self-fulfilling prophecy because positive expectations tend to trigger more favourable outcomes. A strong enough belief in eventual success is bound to make more resilient and persistent efforts in a given research endeavour until its successful completion. An investigator who is optimistic tends to be spurred on to research more and more by success without being discouraged by failure (Allen, 2001). For an optimistic researcher, failure is viewed as a temporary thing, while success is seen as a continuous occurrence as success in one area leads to success in other areas.

The use of metrics such as citation index (number of times that papers published by one researcher are cited by other researchers), i10-index (number of a researcher's publications that have each been cited up to 10 times by other researchers), and particularly $\boldsymbol{h}$-index (the $\boldsymbol{k}$ number of a researcher's publications that have each been cited up to $\boldsymbol{k}$ publications by other researchers) are used typically for judgment of a scholar for faculty positions, promotions, and tenure decisions. Evaluation of the success of a whole department, or even an entire higher institution of learning as done in university rankings world-over, largely depends on the proportion of such metrics that faculty in the department or university have within a specific period, say five years (Nature, 2015). Indeed, the use of metrics like the $\boldsymbol{h}$-index as the most valid and most reliable measure of research productivity has come to stay in the higher education system worldwide (Library Guides, 2017). There are no better ways of measuring scholarly accomplishments globally than the use of such metrics. Every faculty, and indeed, every higher knowledge-based institution must necessarily key in by valuing and encouraging research publications in online journals far higher than local publications. At this radical Information Communication and Technology Age, a research is said to have been published only when it is done online for easy global access (Kpolovie \& Lale, 2017).

To promote quality research, CIIT, for instance, encourages its faculty and students to challenge existing ideas by providing a research-friendly environment and by granting over 850 Research Productivity Awards (RPA) annually (Comsats.edu, 2017). The results have been tremendous. Researchers are highly motivated and inspired to excel, and they do excel in various disciplines. To accelerate research productivity, each university should do the same by annually disbursing Research Productivity Awards (RPA) and conferring monetary awards on researchers in order to acknowledge their successful efforts and motivate healthy faculty 
competition in research productivity. Each published research work that meets the criteria or conditions should be awarded a certificate and a cash prize of $\$ 500$ that could assist the researcher to pay the publication fees for yet another research article in a high impact journal.

\section{Criteria:}

Full name of the University.

Full-length journal publication.

Year of publication, volume, number, and pages.

Google Scholar listing.

The institutionalisation of quantitative evaluation of scholar's research productivity has firmly engendered the giving of incentives to scholars for improved research publications online. For instance, an author's share of $1 \%$ most cited papers increases significantly as his total number of published works online increases. This was revealed by Lariviere and Costas (2016) who studied a sample of 28,078,476 researchers from 1980-2013. "On the average, the higher the number of papers a researcher publishes, the higher the proportion of these papers are amongst the most cited", particularly for older cohorts because it takes some time for a published paper to be read and cited by other investigators. The higher the number of papers an author or a faculty publishes internationally, the more he gets known in the science world, and the greater the citation index and $\boldsymbol{h}$-index that he attracts. A university or a government interested in the research productivity of its faculty cannot avoid monetary compensation of research works that are published internationally.

Faculty research productivity is based on Citation Analysis, which is the science of validly and reliably specifying a researcher's professional impact by counting and accumulating the number of times that each of the researcher's globally published articles is cited by the internationally published articles of other researchers in the world with the aid of available renowned databases or sources like Google Scholar, Web of Science, and Scopus. The supreme, most elaborate and user-friendly method, tool, or metric remarkably adopted widely for the purpose is the Google Scholar h-Index generation (Research Guides, 2016; Google Scholar, 2017). A number of other bibliometrics for research productivity indication also exist, the latest of which is Contemporary h-index, referred to as Hc-Index (Sidiropoulos, Katsaros and Manololoulos, 2006).

In an attempt to better balance the influence of the age of an article and to take care of the rapid increase in the difficulty of getting an additional h-index after when one's h-index has already become high (3 vis-à-vis 10, or 10 vis-à-vis 30), Contemporary H-Index (Hc-Index) was proposed by Sidiropoulos, Katsaros and Manololoulos (2006). The Contemporary HIndex (Hc-Index) provided different corresponding weighs to articles published previously and the ones published recently thus: "For an article published during the current year, its citations account four times. For an article published 4 year ago, its citations account only one time. For an article published 6 year ago, its citations account 4/6 times, and so on. This way, an old article gradually loses its 'value', even if it still gets citations."

This weighting of articles by hc-index accords greater importance to more recently published articles and better encourages very senior scientists in a discipline to continue to publish frequently, instead of relaxing and counting on passed glory as previous bibliometrics had allowed room for, on the one hand. On the other hand, the weighting of articles in the determination of hc-index has made it easier for researchers (both older ones who are still publishing and younger ones) with high h-index already, to more easily gain additional units of h-index. 
Though the hc-index may seem more demanding computationally to decide for each researcher, suitable statistical software has since been developed to overcome such seeming computational difficulties. For instance, the Harzing's Publish or Perish automatically provides the hc-index as part of its bibliometric analyses results, and the Harzing's Publish or Perish software may freely be downloaded from https://harzing.com/ and used with ease. To better take care of the issues, however, Hirsch (2007) postulated the m-index that is a scientist's h-index divided by the number of years since his first publication for better comparison of early stage and late stage scientists by averaging years of low and high productivity across each of the scientists' career. Noorden (2010) hopes to see the day when other methodologies will replace the profusion of bibliometric measures of the prestige of a scientist. Such a day, in my view, is not yet at sight and might not soon be.

\section{Research Questions}

Thirty-five (35) research questions were answered in this study, of which 7 sought to elicit descriptive statistics of each of the variables; 21 sought to establish the correlation coefficients that exist among the variables; and 7 sought to elicit the magnitude to which the predictor variables predict the criterion.

What is the:

1. Mean and standard deviation of Research productivity of the faculty?

2. Mean and standard deviation of Job-satisfaction of the faculty?

3. Mean and standard deviation of Persistence of the faculties?

4. Mean and standard deviation of Optimism of the faculty?

5. Mean and standard deviation of Self-discipline of the faculty?

6. Mean and standard deviation of Motivation of the faculty?

7. Mean and standard deviation of Procrastination of the faculty?

8. Correlation between research productivity and job-satisfaction?

9. Correlation between research productivity and persistence?

10. Correlation between research productivity and optimism?

11. Correlation between research productivity and self-discipline?

12. Correlation between research productivity and motivation?

13. Correlation between research productivity and procrastination?

14. Correlation between job-satisfaction and persistence?

15. Correlation between job-satisfaction and optimism?

16. Correlation between job-satisfaction and self-discipline?

17. Correlation between job-satisfaction and motivation?

18. Correlation between job-satisfaction and procrastination?

19. Correlation between persistence and optimism?

20. Correlation between persistence and self-discipline?

21. Correlation between persistence and motivation?

22. Correlation between persistence and procrastination?

23. Correlation between optimism and self-discipline?

24. Correlation between optimism and motivation?

25. Correlation between optimism and procrastination?

26. Correlation between self-discipline and motivation?

27. Correlation between self-discipline and procrastination?

28. Correlation between motivation and procrastination?

29. Extent to which job-satisfaction, persistence, optimism, self-discipline, motivation, and procrastination, when taken together, predict the research productivity of faculty?

30. Extent to which Job-satisfaction predicts the research productivity of faculty when the other independent variables are controlled for statistically? 
31. Extent to which Persistence single-handedly predicts the research productivity of faculty?

32. Degree to which Optimism predicts the research productivity of faculty when the other independent variables are statistically controlled for?

33. Extent to which Self-discipline unilaterally predicts the research productivity of faculty?

34. Magnitude to which Motivation alone predicts the research productivity of faculty?

35. Magnitude to which Procrastination predicts the research productivity of faculty when the other independent variables are statistically controlled for?

\section{Null Hypotheses}

The outlined 28 null hypotheses, 21 on magnitude and direction of relationships and 7 on magnitude of prediction, were tested at classically recommended alpha.

1. Research productivity and faculty's job-satisfaction do not correlate significantly.

2. Research productivity and faculty's persistence do not correlate significantly.

3. Research productivity and faculty's optimism do not significantly correlate.

4. Research productivity faculty's self-discipline do not significantly correlate.

5. Research productivity and faculty's motivation do not correlate significantly.

6. Research productivity and faculty's procrastination do not significantly correlate.

7. Faculty's job-satisfaction and persistence do not significantly correlate.

8. Job-satisfaction and faculty's optimism do not significantly correlate.

9. Job-satisfaction and faculty's self-discipline do not correlate significantly.

10. Job-satisfaction and faculty's motivation do not correlate significantly.

11. Job-satisfaction and faculty's procrastination do not correlate significantly.

12. Persistence and faculty's optimism do not significantly correlate.

13. Persistence and faculty's self-discipline do not significantly correlate.

14. Persistence and faculty's motivation do not significantly correlate.

15. Persistence and faculty's procrastination do not correlate significantly.

16. Optimism and faculty's self-discipline do not correlate significantly.

17. Optimism and faculty's motivation do not significantly correlate.

18. Optimism and faculty's procrastination do not correlate significantly.

19. Self-discipline and faculty's motivation do not correlate significantly.

20. Self-discipline and faculty's procrastination do not correlate significantly.

21. Motivation and faculty's procrastination do not correlate significantly.

22. When taken together, job-satisfaction, persistence, optimism, self-discipline, motivation, and procrastination do not significantly predict faculty's research productivity.

23. Job-satisfaction does not significantly predict the research productivity of faculty when the other independent variables are controlled for statistically.

24. Persistence does not single-handedly predict the research productivity of faculty significantly.

25. Optimism does not significantly predict the research productivity of faculty when the other independent variables are statistically controlled for.

26. Self-discipline does not unilaterally predict the research productivity of faculty significantly.

27. Motivation alone does not significantly predict the research productivity of faculty.

28. Procrastination does not significantly predict the research productivity of faculty when the other independent variables are statistically controlled for.

\section{METHODOLOGY}

Multiple Prediction Design of Correlational Research Method was employed in the study. Correlation research method is adopted for establishment of the magnitude and nature of relationships between variables. Correlational research method has five designs: 
Simple correlational design

Partial correlational design

Multiple correlation design

Simple prediction design

Multiple prediction design.

The multiple prediction design used for this investigation is the highest and most elaborate of the five correlational research designs (Kpolovie, 2016). With it, the core concerns of each of the other correlational research designs are adequately taken care of. Multiple correlational research design demands application of Multiple Regression statistical test for analysis of collected data to show the extent to which all the independent variables taken together collectively, and taken separately independently, predict the dependent variable (Kpolovie, 2018). While the predictor variables investigated in this study are Job-satisfaction, Persistence, Optimism, Self-discipline, Motivation, and Procrastination; the criterion variable is Research Productivity (h-index).

Never has been a better answer than $\boldsymbol{H}$-Index in the history of science to the question of how to quantify the cumulative impact, relevance, and productivity of a researcher's scientific work. With regards to the differences in publications practices from one profession to another (Peterson, 2005), comparison of researchers within each broad discipline with h-index has remained the best. Mangoes are better compared with mangoes than with coconuts, oranges, guavas, or corns. Consequently, the prediction of research productivity in this investigation was done for only the faculty in the natural sciences (like biology, chemistry, and physics) that study nature. Researchers in the other two main branches of science, social sciences and formal sciences were not included in this study. While social sciences (such as psychology, sociology, economics, and management) studies individuals and societies; the formal sciences (such as mathematics, logic, and theoretical computer science) studies abstract concepts. Researchers in the humanities (like theology, arts, history, philosophy, language and literature) that studies human culture were also not part of the population covered by this investigation.

A sample of 180 was randomly drawn from 24 universities across continents in the world for the study as listed in Table 1.

Table 1: Study sample

\begin{tabular}{|l|l|l|}
\hline CONTINENTS & UNIVERSITIES & Faculty \\
\hline Europe & $\begin{array}{l}\text { University of Vienna; Tomsk State University; } \\
\text { University of Oxford; Sorbonne University. }\end{array}$ & $7 ; 7 ; 8 ; 8$ \\
\hline North America & $\begin{array}{l}\text { California Institute of Technology; Stanford University; } \\
\text { Universidad de Guadalajara; University of Trinidad. }\end{array}$ & $8 ; 8 ; 7 ; 7$ \\
\hline South America & $\begin{array}{l}\text { Federal University of Pernambuco; Central University } \\
\text { of Ecuador; Universidad de Los Andes Colombia; } \\
\text { Pontificia Universidad Catolica de Chile }\end{array}$ & $7 ; 8 ; 8 ; 7$ \\
\hline Oceania & $\begin{array}{l}\text { University of New Zealand; Lincoln University; } \\
\text { University of Hawaii; Australian National University. }\end{array}$ & $8 ; 7 ; 8 ; 7$ \\
\hline Africa & $\begin{array}{l}\text { Nanyang Technology University; University of Hong } \\
\text { Kong; Fudan University; National University of } \\
\text { Singapore. }\end{array}$ & $7 ; 8 ; 8 ; 7$ \\
\hline Total & $\begin{array}{l}\text { University of Ghana; University of Cape Town; } \\
\text { University of Ibadan; University of Botswana. }\end{array}$ & $\mathbf{7 ; 8 ; 8 ; 7}$ \\
\hline
\end{tabular}


Research Productivity of each faculty is the h-index that the scholar has. H-Index refers to a metric that measures the productivity and citation impact of the publications of a scholar, scientist or faculty that represents the K number of the authors' publications that have each been cited by at least K publications of other scientists that are readily available in the World Wide Web as measured by Google Scholar (Kpolovie \& Onoshagbegbe, 2017). The h-index of the sampled faculty were collected online, using Google Scholar search engine.

\section{Instrumentation}

Six self-report inventories, one on each of the predictor variables (Job-satisfaction, Persistence, Optimism, Self-discipline, Motivation, and Procrastination) were developed, validated and used for gathering the data. Each of the self-report inventories had 10 items that were scored on a 1 to 9 scale points:

\begin{tabular}{|l|l|l|l|l|l|l|l|l|}
\hline $\begin{array}{l}\text { Very } \\
\text { poor }\end{array}$ & Poor & $\begin{array}{l}\text { Far } \\
\text { below } \\
\text { average }\end{array}$ & $\begin{array}{l}\text { Below } \\
\text { average }\end{array}$ & Average & $\begin{array}{l}\text { Above } \\
\text { average }\end{array}$ & $\begin{array}{l}\text { Far } \\
\text { above } \\
\text { average }\end{array}$ & Superior & $\begin{array}{l}\text { Very } \\
\text { superior }\end{array}$ \\
\hline 1 & 2 & 3 & 4 & 5 & 6 & 7 & 8 & 9 \\
\hline
\end{tabular}

Thus, 10 and 90, respectively, were the minimum and maximum obtainable score by a faculty on each of the six independent variables. A faculty could only score 10 if he consistently checked Very poor for all the 10 items on a given independent variable. In like manner, a faculty could only score 90 on an independent variable if he consistently checked only Very superior for each of the ten items on an independent variable. The inventories were administered to and received from the participants electronically.

Job-satisfaction was defined operationally as the extent to which a faculty's hopes, expectations, and desires about the lecturing employment that he or she is engaged in are fulfilled as measured by the Job Satisfaction Inventory.

Motivation was operationally defined as the intense drive, zeal, willingness, power, and the actual expression, application or demonstration of the requisite efforts in most successful execution of specific desirable task as measured by the Motivation Inventory.

Optimism was defined as the tendency to see the best in all things, expect only the best possible outcome in everything, and to dwell on just the hopeful aspects of each situation as measured by the Optimism Inventory.

Self-discipline was defined as the ability to and the total commitment to actually make oneself do what one should do, exactly how and when he/she should do it, irrespective of whether he/she feels like doing it or not as measured by the Self-discipline Inventory.

Persistence was defined as the indomitable willpower, unshakable determination, irrepressible commitment, absolute dedication, relentless pursuit, continuous and everincreasing confidence and resolute action in the direction of one's goal until it is exceptionally accomplished as measured by the Persistence Inventory.

Procrastination was defined as the act of frequent postponement, putting off or delaying of an action to a later time; and the demonstration of an absence of haste in getting something done timely as measured by the Procrastination Inventory. 


\section{RESULTS}

The results are as presented in Table 2 .

Table 2: Output of the Multiple Regression

\section{Regression}

\section{Descriptive Statistics}

\begin{tabular}{llll} 
& Mean & Std. Deviation & $\mathrm{N}$ \\
\hline $\begin{array}{l}\text { Research } \\
\text { Productivity }\end{array}$ & 37.3500 & 24.02128 & 180 \\
\hline $\begin{array}{l}\text { Job-satisfaction } \\
\text { Persistence }\end{array}$ & 51.8722 & 19.76341 & 180 \\
\hline Optimism & 52.6611 & 18.06078 & 180 \\
\hline Self-discipline & 51.3167 & 14.85967 & 180 \\
\hline Motivation & 50.0000 & 19.97093 & 180 \\
\hline Procrastination & 52.8056 & 19.15625 & 180 \\
\hline
\end{tabular}

\section{Correlations}

\begin{tabular}{l|l|l} 
Research Job- & Self-
\end{tabular}

Productivity satisfaction Persistence Optimism discipline Motivation Procrastination

\begin{tabular}{|c|c|c|c|c|c|c|c|c|}
\hline \multirow{7}{*}{$\begin{array}{l}\text { Pearson } \\
\text { Correlation }\end{array}$} & Research Productivity & 1.000 & .610 & .660 & .321 & .750 & .698 & -.728 \\
\hline & Job-satisfaction & .610 & 1.000 & .666 & .385 & .759 & .665 & -.441 \\
\hline & Persistence & .660 & .666 & 1.000 & .552 & .761 & .815 & -.482 \\
\hline & Optimism & .321 & .385 & .552 & 1.000 & .523 & .525 & -.336 \\
\hline & Self-discipline & .750 & .759 & .761 & .523 & 1.000 & .815 & -.621 \\
\hline & Motivation & .698 & .665 & .815 & .525 & .815 & 1.000 & -.548 \\
\hline & Procrastination & -.728 & -.441 & -.482 & -.336 & -.621 & -.548 & 1.000 \\
\hline \multirow[t]{7}{*}{ Sig. (1-tailed } & Research Productivity & & .000 & .000 & .000 & .000 & .000 & .000 \\
\hline & Job-satisfaction & .000 & 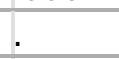 & .000 & .000 & .000 & .000 & .000 \\
\hline & Persistence & .000 & .000 & & .000 & .000 & .000 & .000 \\
\hline & Optimism & .000 & .000 & .000 & . & .000 & .000 & .000 \\
\hline & Self-discipline & .000 & .000 & .000 & .000 & & .000 & .000 \\
\hline & Motivation & .000 & .000 & .000 & .000 & .000 & . & .000 \\
\hline & Procrastination & .000 & .000 & .000 & .000 & .000 & .000 & \\
\hline \multirow[t]{7}{*}{$\mathrm{N}$} & Research Productivity & 180 & 180 & 180 & 180 & 180 & 180 & 180 \\
\hline & Job-satisfaction & 180 & 180 & 180 & 180 & 180 & 180 & 180 \\
\hline & Persistence & 180 & 180 & 180 & 180 & 180 & 180 & 180 \\
\hline & Optimism & 180 & 180 & 180 & 180 & 180 & 180 & 180 \\
\hline & Self-discipline & 180 & 180 & 180 & 180 & 180 & 180 & 180 \\
\hline & Motivation & 180 & 180 & 180 & 180 & 180 & 180 & 180 \\
\hline & Procrastination & 180 & 180 & 180 & 180 & 180 & 180 & 180 \\
\hline
\end{tabular}




\section{Variables Entered/Removed ${ }^{a}$}

\begin{tabular}{|c|c|c|c|}
\hline Model & $\begin{array}{l}\text { Variables } \\
\text { Entered }\end{array}$ & $\begin{array}{l}\text { Variables } \\
\text { Removed }\end{array}$ & Method \\
\hline 1 & $\begin{array}{l}\text { Procrastinati } \\
\text { on, Optimism, } \\
\text { Job- } \\
\text { satisfaction, } \\
\text { Persistence, } \\
\text { Motivation, } \\
\text { Self- } \\
\text { discipline }^{\text {b }}\end{array}$ & & Enter \\
\hline
\end{tabular}

a. Dependent Variable: Research Productivity

b. All requested variables entered.

\section{Model Summaryb}

\begin{tabular}{|c|c|c|c|c|}
\hline Model & $\mathrm{R}$ & R Square & $\begin{array}{l}\text { Adjusted } \\
\text { Square }\end{array}$ & $\begin{array}{c}\text { RStd. Error of } \\
\text { the Estimate }\end{array}$ \\
\hline$\overline{1}$ & $.846^{\mathrm{a}}$ & .715 & .705 & 13.04157 \\
\hline
\end{tabular}

\begin{tabular}{|c|c|c|c|c|c|c|}
\hline \multicolumn{7}{|c|}{ ANOVAa $^{a}$} \\
\hline Model & & $\begin{array}{l}\text { Sum of } \\
\text { Squares }\end{array}$ & $\mathrm{df}$ & Mean Square & $\mathrm{F}$ & Sig. \\
\hline \multirow[t]{3}{*}{1} & Regression & 73862.686 & 6 & 12310.448 & 72.379 & $.000^{\mathrm{b}}$ \\
\hline & Residual & 29424.264 & 173 & 170.082 & & \\
\hline & Total & 103286.950 & 179 & & & \\
\hline
\end{tabular}

a. Dependent Variable: Research Productivity

b. Predictors: (Constant), Procrastination, Optimism, Job-satisfaction, Persistence, Motivation, Self-discipline

\section{Coefficients $^{\mathbf{a}}$}

\begin{tabular}{|c|c|c|c|c|c|c|}
\hline \multirow[b]{2}{*}{ Model } & & \multicolumn{2}{|c|}{$\begin{array}{l}\text { Unstandardized } \\
\text { Coefficients }\end{array}$} & \multirow{2}{*}{$\begin{array}{l}\text { Standardized } \\
\text { Coefficients } \\
\text { Beta }\end{array}$} & \multirow[b]{2}{*}{$\mathrm{t}$} & \multirow[b]{2}{*}{ Sig. } \\
\hline & & $\mathrm{B}$ & Std. Error & & & \\
\hline \multirow[t]{7}{*}{1} & (Constant) & 35.879 & 6.661 & & 5.386 & .000 \\
\hline & Job-satisfaction & 1.084 & .078 & .069 & 1.074 & .284 \\
\hline & Persistence & .241 & .101 & .182 & 2.383 & .018 \\
\hline & Optimism & -.261 & .081 & -.162 & -3.240 & .001 \\
\hline & Self-discipline & .326 & .106 & .271 & 3.059 & .003 \\
\hline & Motivation & .179 & .107 & .138 & 1.672 & .096 \\
\hline & Procrastination & -.527 & .065 & -.420 & -8.059 & .000 \\
\hline
\end{tabular}

a. Dependent Variable: Research Productivity

There are six sections in the Multiple Regression Output as shown in Table 2 - Descriptive Statistics, Correlations, Variables Entered, Model Summary, ANOVA, and Coefficients. Each of them is briefly interpreted. 


\section{Descriptive Statistics}

The Mean and Std. Deviation are provided here for each of the seven variables. The $\mathrm{N}$ is 180 . The Mean and Std. Deviation are respectively 37.3500 and 24.02128 for Research Productivity, 51.8722 and 19.76341 for Job-satisfaction, 52.6611 and 18.06078 for Persistence, 51.3167 and 14.85967 for Optimism, 50.0000 and 19.97093 for Self-discipline, 52.1722 and 18.48080 for Motivation, and 52.8056 and 19.15625 for Procrastination. The descriptive statistics provided in this section are answers to the first seven of the research questions.

\section{Correlations}

The Correlations table of the Output is a display of Pearson Correlation Coefficient for each of the possible 21 bivariate correlations of the seven variables:

i. Research Productivity and Job-satisfaction, $\mathrm{r}=.610, \mathrm{p}<.01$.

ii. Research Productivity and Persistence, $r=.660, p<.01$.

iii. Research Productivity and Optimism, $\mathrm{r}=.321, \mathrm{p}<.01$.

iv. Research Productivity and Self-discipline, $r=.750, p<.01$.

v. Research Productivity and Motivation, $r=.698, \mathrm{p}<.01$.

vi. Research Productivity and Procrastination, $r=-.728, \mathrm{p}<.01$.

vii. Job-satisfaction and Persistence, $r=.666, \mathrm{p}<.01$.

viii. Job-satisfaction and Optimism, $r=.385, \mathrm{p}<.01$.

ix. Job-satisfaction and Self-discipline, $r=.759, \mathrm{p}<.01$.

$\mathrm{x}$. Job-satisfaction and Motivation, $\mathrm{r}=.665, \mathrm{p}<.01$.

xi. Job-satisfaction and Procrastination, $\mathrm{r}=-.441, \mathrm{p}<.01$.

xii. Persistence and Optimism, $\mathrm{r}=.552, \mathrm{p}<.01$.

xiii. Persistence and Self-discipline, $r=.761, p<.01$.

xiv.Persistence and Motivation, $\mathrm{r}=.815, \mathrm{p}<.01$.

$\mathrm{xv}$. Persistence and Procrastination, $r=-.482, \mathrm{p}<.01$.

xvi.Optimism and Self-discipline, $r=.523, \mathrm{p}<.01$.

xvii. Optimism and Motivation, $r=.525,<.01$.

xviii. Optimism and Procrastination, $\mathrm{r}=-.336, \mathrm{p}<.01$.

$x i x$.Self-discipline and Motivation, $r=.815, \mathrm{p}<.01$.

$\mathrm{xx}$. Self-discipline and Procrastination, $\mathrm{r}=-.621, \mathrm{p}<.01$.

xxi. Motivation and Procrastination, $r=-.548, \mathrm{p}<.01$.

These correlation coefficients are answers to their corresponding research questions. The correlation coefficients serve as additional descriptive information on the complex interrelationships that exist among the seven variables under investigation. If the study had merely been for purposes of establishing the bivariate linear relationships between the variables of interest, conclusions could have been drawn from the magnitude and nature of the associations between the variables that each of the bivariate correlations is statistically significant at .01, with moderate to very large effect sizes. But the concern of the investigation goes far beyond provision of the bivariate correlation coefficients between the variables to squarely deal with the extent to which Research Productivity can be predicted jointly by the six predictor variables, and partially by each of the six independent variables - Job-satisfaction, Persistence, Optimism, Self-discipline, Motivation, and Procrastination; when influence of the other variables are controlled for.

\section{Variables Entered/Removed}

This table merely summarised the variables entered simultaneously in the prediction or regression model to be all the six predictor variables and the one criterion variable. Thus, no variable was "Removed". 


\section{Model Summary}

The much-needed $R, R$ Square, and Adjusted $R$ Square, as well as the Std. Error of the Estimate are displayed in the Model Summary section of the output. While the Std. Error of Estimates is a measure of the extent to which Research Productivity was not predicted from the six predictor variables; the $R, R$ Square and Adjusted $R$ Square are measures of the extent to which the six independent variables (Job-satisfaction, Persistence, Optimism, Self-discipline, Motivation and Procrastination) jointly predicted the criterion variable, Research Productivity.

The $R$ of .846 is known as Multiple Correlation Coefficient. The Multiple Correlation Coefficient $(R)$ is the coefficient that best depicts the relationship that exists between one dependent (criterion) variable and two or more independent (predictor) variables when the latter are taken together. It is the correlation between the criterion variable and the best linear combination of the predictor variables simultaneously. The $R$ that depicts Multiple Correlation or Multiple Regression is someway like the $r$ in Pearson Product Moment Correlation. But while $r$ is the linear relationship between an independent variable and a dependent variable, the Multiple Correlation Coefficient $(R)$ is the linear relationship between many independent variables synchronously with one dependent variable.

Essentially, $R$ represents the correlation coefficient between the actual scores on the dependent variable (Research Productivity in this case) and the predicted scores of the dependent variable on the basis of the independent variables (Job-satisfaction, Persistence, Optimism, Self-discipline, Motivation and Procrastination, in this case) taken together as captured by the Multiple Regression Equation. Simply put, the Multiple $R$ is the correlation between the criterion scores and the predicted values of the criterion based on the many predictor variables. The predicted values of the criterion are arrived at via the Multiple Regression Equation on the one criterion and many predictor variables. That is, the Multiple Regression or Multiple Correlation that is symbolised $R$ in this example, is the absolute value of the correlation between the original Research Productivity scores and the Research Productivity scores that are predicted from the six independent variables (Job-satisfaction, Persistence, Optimism, Self-discipline, Motivation and Procrastination). In fact, it is this factor that makes the $R$ in Multiple Regression to be different from the $R$ in Simple Regression.

The $R$ Square $\left(R^{2}\right)$ of .715 is indeed the square of $R(.846 \times .846=.715)$ as the name implies. When the $R^{2}$ is multiplied by 100 , it becomes what known as Coefficient of Multiple Determination, which is the percentage of total variance in the dependent variable that is simultaneously accounted for by the many independent variables. Multiple Regression elicits the proportion of variance in the criterion variable that is attributable to the linear combination of several predictor variables $\left(R^{2} \mathrm{x} 100\right)$. In this study, the six predictor variables - Job-satisfaction, Persistence, Optimism, Self-discipline, Motivation and Procrastination synchronously account for $71.5 \%$ of the variance in faculty's Research Productivity.

The Adjusted $R$ Square of .705 is a modified value of $R$ Square in order to improve estimation of the true population value of the dependent variable by preventing even the slight probability of the computed $R^{2}$ from overestimating the population value. The calculated $R^{2}$ based on the sample, tends to overestimate the population value. Adjusted $\mathrm{R}^{2}$ is used for modification of the sample value to guarantee more accuracy in estimation of the population value.

The Std. Error of the Estimate of 13.04157 is the degree to which the six predictor variables were not able to predict values of the criterion variable (Research Productivity). That is, when using Job-satisfaction, Persistence, Optimism, Self-discipline, Motivation and Procrastination to 
simultaneously predict Research Productivity, the Regression Equation missed 13.04157 points on the average in accurately predicting Research Productivity.

\section{ANOVA}

The ANOVA section of the results is used to test the overall Multiple Regression $(R)$ for statistical significance. The Multiple Regression ANOVA seeks to establish overall contributions of the entire independent variables to the variance in the criterion variable (Research Productivity). The ANOVA section in Multiple Regression is used to answer the important question of multiple correlation on whether the entire set of predictor variables taken together predict Y (the dependent variable) at better-than-chance levels. This question is of most crucial importance in Multiple Regression because there is little point in looking for the contribution of the individual predictor variables separately on the dependent variable if no overall significant contribution of all the predictor variables taken together exists on the criterion. Thus, the ANOVA in the Multiple Regression output is a statistical test of whether the regression model with all of the six entered predictors (Job-satisfaction, Persistence, Optimism, Self-discipline, Motivation and Procrastination) predicts Research Productivity significantly. In other words, the ANOVA tests whether the $R^{2}$ of .715 is significantly greater than zero. Like the typical One-Way Analysis of Variance, the ANOVA in Multiple Regression functions thus: if the $F$ has Sig. ( $p$-value) that is less than or equal to the classical .05 alpha, then the regression model with all the independent variables entered or included, significantly predicts the scores on the dependent variable. On the contrary, if the $F$ has a $p$-value (Sig.) that is greater than .05 , the regression model of all the entered independent variables do not predict the dependent variable significantly.

In the Output under consideration, the ANOVA table has shown 73862.686 Sum of Squares, 6 df, and 12310.448 Mean Square for the Regression (that is akin to Between Groups). The Residual (that is like Within Groups) has 29424.264 Sum of Squares, $173 \mathrm{df}$, and 170.082 Mean Square. The Total Sum of Squares is 103286.950 , and df of 179. The computed $F$ is 72.379 with Sig. of .000 that is read as less than .0005. Since the Sig. of .000 is smaller than the chosen alpha of .01, the first null hypothesis that "when taken together, job-satisfaction, persistence, optimism, self-discipline, motivation, and procrastination do not significantly predict the research productivity of faculty" is rejected. Therefore the alternate hypothesis that "when taken together, job-satisfaction, persistence, optimism, self-discipline, motivation, and procrastination significantly predict the research productivity of faculty" is upheld, $[\boldsymbol{F}(\mathbf{6}, \mathbf{1 7 3})$ $\left.=72.379, p<.01, R^{2}=.715\right]$. That is, indeed, the Multiple Regression model with all the six predictors included $\left(R^{2}\right)$, is significantly different from zero; as job-satisfaction, persistence, optimism, self-discipline, motivation, and procrastination (taken together) simultaneously predict Research Productivity to the extent that $71.5 \%$ of the variance in Research Productivity is accounted for by the predictors.

The measure of Effect Size in multiple regression, according to Cohen (1988) is $R^{2}$. The $R^{2}$ of ".02, .13, and .26" are recommended by him (Cohen, 1988) as "small, medium, and large" effect sizes, respectively. Thus, the $.715 R^{2}$ arrived at in this example is a very large effect size.

\section{Coefficients}

The sixth section of the Output, called Coefficients, is used for two major functions - (i) testing for significance of the individual predictors, and (ii) construction of the Multiple Regression Equation. 


\section{Testing for Significance of each Predictor}

The first column (Model) that has the individual predictors listed; and the last three columns in the Coefficients table that respectively provide Standardized Coefficients Beta, $t$ and Sig. ( $p$ value) are for testing each of the independent variables to know whether it significantly predicts the dependent variable. Testing of the omnibus Multiple Regression model for significance, though this has earlier been done by the ANOVA table, is not left out in the Coefficients table. Let me very quickly list these tests of significance and take the right decision on each, whether it is significantly predicting the criterion (Research Productivity) or not. The degrees of freedom for each of the $t$-tests in multiple regression are the number of participants $(\mathrm{N})$ minus the number of predictors $(\mathrm{P})$ minus one (1). That is, $\mathrm{df}=\mathrm{N}-\mathrm{P}-1$.

1. Constant is used for testing the omnibus Multiple Regression model, and it has a Standardized Coefficient Beta of .846 (as indicated for the multiple regression $R$ ), $t$ of 5.386 and Sig. of .000 (read as less than .0005). Since the Sig. (.000) is less than the .01 alpha, the first null hypothesis that "when taken together, job-satisfaction, persistence, optimism, self-discipline, motivation, and procrastination do not significantly predict the research productivity of faculty" is rejected. All the six independent variables collectively predict Research Productivity significantly $[\boldsymbol{\beta}=\mathbf{. 8 4 6}, \boldsymbol{t}(\mathbf{1 7 3})=\mathbf{5 . 3 8 6}, \boldsymbol{p}<$ $\left..01, R^{2}=.715\right]$.

2. Job-satisfaction has a Standardized Coefficient Beta $(\beta)$ of .069 , a $t$ of 1.074 , and Sig. of .284. The Sig. (.284) is greater than .05 alpha. Therefore, the second null hypothesis that "job-satisfaction does not significantly predict the research productivity of faculty when the other independent variables are controlled for statistically" is retained. Jobsatisfaction alone, without the influence of any of the other predictors, does not significantly predict Research Productivity $[\boldsymbol{\beta}=.069, \boldsymbol{t}(173)=\mathbf{1 . 0 7 4}, \boldsymbol{p}>\mathbf{. 0 5}]$.

3. Persistence has a Standardized Coefficient Beta $(\beta)$ of .182, a $t$ of 2.383, and Sig. of .018. The Sig. (.018) is lower than .05 alpha. Therefore, the third null hypothesis that "persistence does not single-handedly predict the research productivity of faculty significantly" is rejected. Persistence unilaterally (without the influence of any of the other predictors) significantly predicts Research Productivity $[\boldsymbol{\beta}=\mathbf{. 1 8 2}, \boldsymbol{t}(\mathbf{1 7 3})=$ $2.383, p<.05]$.

4. Optimism has a Standardized Coefficient Beta $(\beta)$ of -.162 , a $t$ of -3.240 , and Sig. of .001 . The Sig. (.001) is less than .01 alpha. Therefore, the fourth null hypothesis that "optimism does not significantly predict the research productivity of faculty when the other independent variables are statistically controlled for" is rejected. Optimism distinctly (without the effect of any of the other predictors) significantly predicts

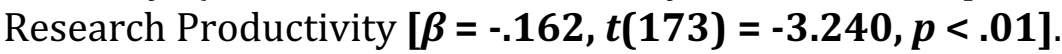

5. Self-discipline has a Standardized Coefficient Beta $(\beta)$ of .271, a $t$ of 3.059, and Sig. of .003. The Sig. (.003) is less than .01 alpha. Therefore, the fifth null hypothesis that "selfdiscipline does not unilaterally predict the research productivity of faculty significantly" is rejected. Self-discipline alone (without the effect of any of the other independent variables) significantly predicts faculty's Research Productivity $[\boldsymbol{\beta}=. \mathbf{2 7 1}, \boldsymbol{t}(\mathbf{1 7 3})=$ $3.059, p<.01]$.

6. Motivation has a Standardized Coefficient Beta $(\beta)$ of .138, a $t$ of 1.672, and Sig. of .096. The Sig. (.096) is greater than .05 alpha. Therefore, the sixth null hypothesis that "Motivation alone does not significantly predict the research productivity of faculty" is retained. Motivation, when taken unilaterally, without the effect of any of the other independent variables, does not significantly predict Research Productivity $[\boldsymbol{\beta}=\mathbf{. 1 3 8}$, $t(173)=1.672, p>.05]$.

7. Procrastination has a Standardized Coefficient Beta $(\beta)$ of -.420 , a $t$ of -8.059 , and Sig. of .000 (read as less than .0005). The Sig. (.000) is less than .01 alpha. Therefore, the 
seventh null hypothesis that "procrastination does not significantly predict the research productivity of faculty when the other independent variables are statistically controlled for" is rejected. Procrastination alone (without the effect of any of the other independent variables) significantly predicts faculty's Research Productivity negatively $[\boldsymbol{\beta}=-.420, \boldsymbol{t}(\mathbf{1 7 3})=\mathbf{- 8 . 0 5 9}, \boldsymbol{p}<. \mathbf{0 1}]$. That is, lower procrastination aids improved research productivity.

\section{Construction of the Multiple Regression Equation}

The necessary values for construction of Multiple Regression Equation are presented in the first two columns (Model and Unstandardized Coefficient $B$ ) in the Coefficients table of the output. Multiple Regression Equation with six independent variables for prediction of the dependent variable is created thus:

$$
\hat{Y}=a+b_{1} \mathrm{X}_{1}+b_{2} \mathrm{X}_{2}+b_{3} \mathrm{X}_{3}+b_{4} \mathrm{X}_{4}+b_{5} \mathrm{X}_{5}+b_{6} \mathrm{X}_{6}
$$

Where:

$\hat{Y}_{\mathrm{i}}=$ the predicted value of the dependent variable (Research Productivity) for the ith participant based on the ith participant's cores in the six predictor variables.

$a=$ the $Y$-intercept or Constant term, which refers to the value of $\hat{Y}$ when every of the $\mathrm{X}=0$.

$b_{1}=$ the regression coefficient for the first predictor (Job-satisfaction).

$b_{2}=$ the regression coefficient for the second predictor (Persistence).

$b_{3}=$ the regression coefficient for the third predictor (Optimism).

$b_{4}=$ the regression coefficient for the fourth predictor (Self-discipline).

$b_{5}=$ the regression coefficient for the fifth predictor (Motivation).

$b_{6}=$ the regression coefficient for the sixth predictor (Procrastination).

$\mathrm{X}_{1}=$ the score on the first predictor (Job-satisfaction) for participant $\mathrm{i}$.

$\mathrm{X}_{2}=$ the score on the second predictor (Persistence) for participant $\mathrm{i}$.

$\mathrm{X}_{3}=$ the score on the third predictor (Optimism) for participant $\mathrm{i}$.

$\mathrm{X}_{4}=$ the score on the fourth predictor (Self-discipline) for participant $\mathrm{i}$.

$\mathrm{X}_{5}=$ the score on the fifth predictor (Motivation) for participant $\mathrm{i}$.

$\mathrm{X}_{6}=$ the score on the sixth predictor (Procrastination) for participant $\mathrm{i}$.

In the Coefficients table of the Multiple Regression output, the values for creation of the Multiple Regression Equation are found in the Unstandardized Coefficient $B$ column. The names of the Constant, $a$, and the predictor variables $\left(b_{1}, b_{2}, b_{3}, b_{4}, b_{5}\right.$, and $b_{6}$, respectively for Job-satisfaction, Persistence, Optimism, Self-discipline, Motivation, and Procrastination) are found in the Model column. Therefore, the names and actual values for construction of the Multiple Regression Equation are as follows:

$a=$ Constant $=35.879$

$b_{1}=$ Job-satisfaction $=.084$

$b_{2}=$ Persistence $=.241$

$b_{3}=$ Optimism $=-.261$

$b_{4}=$ Self-discipline $=.326$

$b_{5}=$ Motivation $=.179$

$b_{6}=$ Procrastination $=-.527$.

When these actual values are substituted into the Multiple Regression Equation formula, the predicted Research Productivity $\left(\hat{Y}_{\mathrm{i}}\right)$ for the first three faculties will become as illustrated below. The first three faculty's scores on the six predictor variables are as follows. 


\begin{tabular}{|l|l|l|l|l|l|l|}
\hline Faculty & Jobsatis & Persist & Optimism & Selfdisc & Motivate & Procrast \\
\hline 1 & 18 & 40 & 42 & 31 & 34 & 82 \\
\hline 2 & 19 & 26 & 34 & 22 & 25 & 60 \\
\hline 3 & 20 & 20 & 33 & 20 & 27 & 75 \\
\hline
\end{tabular}

The multiple regression equation of $\hat{Y}=a+b_{1} \mathrm{X}_{1}+b_{2} \mathrm{X}_{2}+b_{3} \mathrm{X}_{3}+b_{4} \mathrm{X}_{4}+b_{5} \mathrm{X}_{5}+b_{6} \mathrm{X}_{6}$ was constructed as:

$\hat{Y}_{\text {research productivity }}=35.879+.084\left(\mathrm{X}_{\text {job-satisfaction }}\right)+.241\left(\mathrm{X}_{\text {persistence }}\right)+-.261\left(\mathrm{X}_{\text {optimism }}\right)+.326\left(\mathrm{X}_{\text {self- }}\right.$ discipline $)+.179\left(\mathrm{X}_{\text {motivation }}\right)+-.527\left(\mathrm{X}_{\text {procrastination }}\right)$.

For Faculty $1: \hat{Y}_{\mathrm{i}}=35.879+.084(18)+.241(40)+-.261(42)+.326(31)+.179(34)+-.527(82)$ $=9.047$.

For Faculty 2: $\hat{Y}_{i}=35.879+.084(19)+.241(26)+-.261(34)+.326(22)+.179(25)+-.527(60)$ $=14.894$.

For Faculty 3: $\hat{Y}_{\mathrm{i}}=35.879+.084(20)+.241(20)+-.261(33)+.326(20)+.179(27)+-.527(75)$ $=5.594$.

Recall that residual values are the difference between the actual observed criterion scores and the predicted criterion scores. A major reason for execution of Multiple Regression is prediction of the criterion variable scores on the basis of known predictor variables scores. This accounts for why the predicted Research Productivity scores based on scores in the six predictor variables for each faculty demands tabulation.

The multiple regression equation of $\hat{Y}=a+b_{1} \mathrm{X}_{1}+b_{2} \mathrm{X}_{2}+b_{3} \mathrm{X}_{3}+b_{4} \mathrm{X}_{4}+b_{5} \mathrm{X}_{5}+b_{6} \mathrm{X}_{6}$ was constructed as:

$\hat{Y}_{\text {research productivity }}=35.879+.084\left(\mathrm{X}_{\text {job-satisfaction }}\right)+.241\left(\mathrm{X}_{\text {persistence }}\right)+-.261\left(\mathrm{X}_{\text {optimism }}\right)+.326\left(\mathrm{X}_{\text {self- }}\right.$ discipline $)+.179\left(\mathrm{X}_{\text {motivation }}\right)+-.527\left(\mathrm{X}_{\text {procrastination }}\right)$.

Based on this multiple regression equation, the predicted values, as well as the residual values for research productivity of faculty, are as displayed in Table 3 that is placed just after the 'References'.

\section{CONCLUSIONS}

Research Productivity is measured with h-index. So much empirical attention has been accorded to how the research accomplishments of scientists can be measured without commensurate devotion to investigation of factors that could predict the productivity of scientists. This investigation adopted multiple prediction design for the prediction of Research Productivity from faculty's job-satisfaction, persistence, optimism, self-discipline, motivation and procrastination. Mean and Std. Deviation were used to describe each of the variables, and to answer the first seven research questions. Bivariate correlation coefficients were provided as answers to the next 21 of the research questions. Each of the 21 null hypotheses on correlation was rejected as the relationship is significant at .0005 alpha.

For testing the null hypotheses, the overall multiple regression showed that when taken together, job-satisfaction, persistence, optimism, self-discipline, motivation, and procrastination significantly predict research productivity, $\left[\boldsymbol{F}(\mathbf{6}, \mathbf{1 7 3})=\mathbf{7 2 . 3 7 9}, \boldsymbol{p}<. \mathbf{0 1}, \boldsymbol{R}^{\mathbf{2}}=\right.$ .715]. It can also be expressed that all the six independent variables collectively predict faculty's Research Productivity significantly $[\boldsymbol{\beta}=. \mathbf{8 4 6}, \boldsymbol{t}(173)=5.386, p<.01]$. Taking the predictors separately, the results have shown that: 
Job-satisfaction alone, without the influence of any of the other predictors, does not significantly predict faculty's Research Productivity $[\boldsymbol{\beta}=.069, \boldsymbol{t}(173)=1.074, p>.05]$.

Persistence unilaterally (without the influence of any of the other predictors) significantly predicts faculty's Research Productivity $[\boldsymbol{\beta}=\mathbf{. 1 8 2}, t(173)=\mathbf{2 . 3 8 3}, \boldsymbol{p}<.05]$.

Optimism singlehandedly predicts faculty's Research Productivity significantly $[\boldsymbol{\beta}=-\mathbf{1 6 2}$, $t(173)=-3.240, p<.01]$.

Self-discipline distinctly predicts faculty's Research Productivity significantly $[\boldsymbol{\beta}=\mathbf{. 2 7 1}, \boldsymbol{t}(\mathbf{1 7 3})$ $=3.059, p<.01]$.

Motivation alone does not significantly predict faculty's Research Productivity $[\boldsymbol{\beta}=\mathbf{. 1 3 8}$, $\boldsymbol{t}(\mathbf{1 7 3})=\mathbf{1 . 6 7 2}, \boldsymbol{p}>\mathbf{. 0 5}$ ]. One cannot become a highly productive researcher or scientist if he has to wait for motivation in the form of sponsorship or research grant before serious engagement in research execution.

Procrastination alone (without the effect of any of the other independent variables) significantly predicts Research Productivity of faculty $[\boldsymbol{\beta}=.271, t(173)=3.059, p<.01]$.

Multiple regression equation was created as follows:

$\hat{Y}_{\text {research productivity }}=35.879+.084\left(\mathrm{X}_{\text {job-satisfaction }}\right)+.241\left(\mathrm{X}_{\text {persistence }}\right)+-.261\left(\mathrm{X}_{\text {optimism }}\right)+.326\left(\mathrm{X}_{\text {self- }}\right.$ discipline $)+.179\left(\mathrm{X}_{\text {motivation }}\right)+-.527\left(\mathrm{X}_{\text {procrastination }}\right)$.

Based on the multiple regression equation, the predicted values, as well as the residual values for research productivity, are tabulated just after the 'References'.

The findings have shown that to most likely improve research productivity, a scientist should improve his/her personal self-discipline, persistence, and optimism; and exterminate procrastination. While the first three variables, self-discipline, persistence and optimism (particularly self-discipline and persistence) are very good positive predictors of research productivity, procrastination is a dominant negative predictor of faculty's research productivity. The more the procrastination, the lower the research productivity of a scientist.

Job-satisfaction and motivation do not significantly predict faculty's research productivity. Over satisfaction with one's job as a lecturer may not propel him to regularly execute research. One cannot become a highly productive researcher or scientist if he has to wait for motivation in the form of sponsorship or research grants before serious engagement in research execution.

Finally, a professor in the natural sciences is expected to have h-index that is not less than 37.35, which is the average research productivity of faculty in this branch of science. Professors in the natural science whose research productivity (h-index) is yet to exceed the world average need to exert extra efforts in research execution to continue to play significant leading role as models for younger scholars in the ever-changing information and communication technology-lead world.

Frequent writing, at least four times of 30 minutes per day is the silver-bullet for research productivity and for an all-round brilliant scholarly accomplishments. Write very often. Express your thoughts in writing. Learn to write a significant part of everything you think of. There is no better way to concentrate, clarify your thoughts, and become more creative than deliberate practice. Practice writing four times, at least 30 minutes each time, every day. 
Persevere unstoppably in four writing sessions of at least 30 minutes per session every day. Write early in the morning, write before launch, write in the evening, and wake up at night to write. One who writes for at least 30 minutes, four times each day; most successfully invests at least two hours per day in writing. Individuals with high research productivity, h-Index of 37.35 and above, have typically invested two hours in writing per day on the average. Persistence in writing for many hours every day is indispensable for improved research productivity. H-Index (research productivity) that far exceeds the world average (37.35), could most likely not be achieved by anyone, in the natural sciences in particular, without at least two hours of daily writing as revealed by additional data of this investigation.

\section{References}

Academic Voice (2017). Developing a Purposeful Writing Practice. Retrieved from https://mail.google.com/mail/u/1/\#inbox/16010fa8ebe7d212.

Allen, D. (2001). Getting things done: The art of stress-free productivity. New York: Viking Penguin.

Altbach, P.G. (2015). What Counts for Academic Productivity in Research Universities? International Higher Education. Number 79. Retrieved from https://ejournals.bc.edu/ojs/index.php/ihe/article/view/5837/5201

Becker Guides (2016). Quantifying the impact of my publications: What is the h-index?

http://beckerguides.wustl.edu/c.php?g=299569\&p=2001203.

Comsats.edu (2017). Research Productivity Awards.

http://ww3.comsats.edu.pk/ORIC/ResearchProductivityAwards.aspx.

Egghe, L. (2006). Theory and practise of the g-Index. Scientometrics. 69(1), 131-152. Retrieved from https://link.springer.com/article/10.1007\%2Fs11192-006-0144-7

Google Scholar (2017). Google Scholar Metrics. https://scholar.google.com/intl/en/scholar/metrics.html.

Harzing, A-W. (2010). The Publish or Perish book: Your guide to effective and responsible citation analysis. London, UK: Tarma Software Research.

Harzing, A-W. (2017). Bibliometrics and Citation Searching: Publish or Perish. Retrieved from https://libguides.ioe.ac.uk/c.php?g=482227\&p=3298955

Harzing, A-W. (2017). Metrics: $h$ and g-index. Retrieved from https://harzing.com/resources/publish-orperish/tutorial/metrics/h-and-g-index.

Hey, T; Tansley, S.; Tolle, K. (2009). The Fourth Paradigm. Data-Intensive Science Discovery. Microsoft Research, Redmond, Washington. Retrieved from http://research.Microsoft.com/en-us/collaboration/fourthparadign.

Hirsch, J.E. (2005). An index to quantify an individual's research output. Proceedings of the National Academy of Science of the United States. 15(102), 16569-16572. Retrieved from http://www.pnas.org/content/102/46/16569

Hirsch, J.E. (2007). Does the h-index have predictive power? Proceedings of the National Academy of Science of the United States. 104(49), 19193-19198. Retrieved from http://www.pnas.org/content/104/49/19193.full

Kern, S. (2011). Analytic model for academic research productivity having factors, interactions and implications. Cancer Biology \& Therapy. 12(11), 949-956. Retrieved from https://www.ncbi.nlm.nih.gov/pmc/articles/PMC3280913/.

Kpolovie, P.J.; Akpelu, W.D. (2017). Educational software impact on technology mediated learning. International Journal of Network and Communication Research. 4(1), 1-33. Retrieved from http://www.eajournals.org/wpcontent/uploads/Educational-Software-Impact-on-Technology-Mediated-Learning.pdf

Kpolovie, P.J.; Lale, N.E.S. (2017). Adaptation and globalization of university curriculum with LMSs in the changing world. European Journal of Computer Science and Information Technology. 5(2), 28-89. Retrieved from http://www.eajournals.org/wp-content/uploads/Globalization-and-Adaptation-of-University-Curriculum-toLMSS-with-the-Changing-World.pdf

Kpolovie, P.J.; Obilor, I.E. (2013). Nigerian universities bag ludicrous ranks in world rankings of universities. Universal Journal of Education and General Studies.

http://universalresearchjournals.org/ujegs/pdf/2013/September/Kpolovie\%20and\%200b ilor.pdf universities. International Journal of Quantitative and Qualitative Research Methods. Retrieved from 
http://www.eajournals.org/wp-content/uploads/Research-Productivity-h-Index-and-I10-Index-of-Academics-inNigerian-Universities.pdf

Kpolovie, P.J. (2013). Quality assurance in the Nigerian educational system: Matters arising. International Journal of Scientific Research in Education. 6(4), 1-85. Retrieved from www.ijsre.com/assets/vol.\%2C-6(4)-kpolovie.pptx

Kpolovie, P.J. (2016). Excellent research methods. Indiana, United States: Partridge publishing. www.kpoloviepj.com

Kpolovie, P.J. (2018). Statistical approaches in excellent research methods. Indiana, USA: Partridge Publishing. www.kpoloviepj.com

Kpolovie, P.J.; Awusaku, O.K. (2016). ICT adoption attitude of lecturers. European Journal of Computer Science and Information Technology. 4(5), 9-57. http://www.eajournals.org/wp-content/uploads/ICT-Adoption-Attitude-ofLecturers.pdf

Kpolovie, P.J.; Ewansiha, S.; Esara, M. (2017). Continental comparison of Human Development Index (HDI).

International Journal of Humanities Social Sciences and Education (IJHSSE). 4(1), 9-27.

https://www.arcjournals.org/pdfs/ijhsse/v4-i1/2.pdf

Larivière, V.; Costas, R. (2016). How many is too many? On the relationship between research productivity and impact. PLoS ONE 11(9): e0162709. Retrieved from

http://journals.plos.org/plosone/article?id=10.1371/journal.pone.0162709.

Leonelli, S. (2014). Data Interpretation in the Digital Age. European PMC Founders. Retrieved from https://www.ncbi.nlm.nih.gov/PMC/articles/PMC4340525.

Library Guides (2017). Assessing article and author influence: Finding an author's H-Index. Retrieved from HTTP://LIBGUIDES.BC.EDU/ARTICLEINFLUENCE/HINDEX.

Likert, R. (1932). A technique for measurement of attitude. Archives of Psychology. 22, 5-55.

Marnett, A. (2017). H-Index: What it is and how to find yours. BENCH FLY. Retrieved from http://www.benchfly.com/blog/h-index-what-it-is-and-how-to-find-yours/

Martin, B. (2009). Research productivity: some paths less travelled. Australian Universities' Review. 51(1), 14-20. Retrieved from https://www.uow.edu.au/ bmartin/pubs/09aur.html

Mattmight (2015). Productivity tips, tricks and hacks for academics. http://matt.might.net/articles/productivitytips-hints-hacks-tricks-for-grad-students-academics/

Mueller, C.E.; Gaus, H.; Konradt, I. (2016). Predicting research productivity in International Education Journals across Countries. Journal of MultiDisciplinary Evaluation. 12(27), 79-92. Retrieved from http://journals.sfu.ca/jmde/index.php/jmde_1/article/view/459.

Nature (2015). How should we measure research productivity? Retrieved from http://www.nature.com/scitable/blog/watching-the-detectives/how_should_we_measure_research

NIH Library (2018). NIH Library Writing Centre: Impact Factor \& h-index. Retrieved from http://nihlibrary.campusguides.com/c.php?g=38330\&p=244518.

Noorden, R.V. (2010). Metrics: a profusion of measures. Nature. 465, 864-866 doi:10.1038/465864a. Retrieved from http://www.nature.com/news/2010/100616/full/465864a.html

Pacheco-Vega, R. (2013). My top 10 academic productivity tip, or how I submitted 5 pieces in 3 weeks. Retrieved from http://www.raulpacheco.org/2013/04/my-top-10-academic-productivity-tips-or-how-i-submitted-5pieces-in-3-weeks/

Peterson, I. (2005). Rating researchers. Science News. Retrieved from https://www.sciencenews.org/article/rating-researchers

Research Guides (2016). Measuring your impact: Impact factor; Citation analysis, and other metrics. Retrieved from http://researchguides.uic.edu/c.php?g=252299\&p=1683205.

Research Guides (2016). Measuring your impact: Impact factor; Citation analysis, and other metrics. Retrieved from http://researchguides.uic.edu/c.php?g=252299\&p=1683205

Scribeendi.com (2018). Publish or Perish: How to survive in academia. Retrieved from https://www.scribendi.com/advice/publish_or_perish.en.html.

Sidiropoulos, A.; Katsaros, D.; Manolopoulos, Y. (2006). Generalised h-index for disclosing latent facts in citation networks. arXiv:cs.DL/0607066 (1), 1-19. 
Spicer, A. (2015). Explainer: What is an H-index and how is it calculated? http://theconversation.com/explainerwhat-is-an-h-index-and-how-is-it-calculated-41162.

Thesis Whisperer (2016). Super charged academic productivity? https://thesiswhisperer.com/2016/04/06/gettingthingsdone/

Table 3: Predicted and residual values of research productivity

\begin{tabular}{|c|c|c|c|c|c|c|c|c|c|}
\hline Eile Edit & View Data & Iransform & Analyze & Graphs Uيtilitie & s Extensions & Is $\underline{\text { Window }}$ & Help & & \\
\hline \multicolumn{2}{|c|}{ 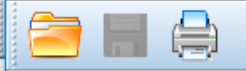 } & $\sqrt{5}$ & 置 & 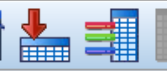 & 뵤묘 & 需曲 & 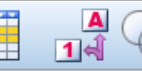 & + & \\
\hline & \multicolumn{2}{|c|}{ \& Productiv \& Jobsatis } & $\&$ Persist & Optimism & $\&$ Selfdisc & $\&$ Motivate & \& Procrast & \& PRE_1 & \& RES_1 \\
\hline 1 & 20.00 & 18.00 & 40.00 & 42.00 & 31.00 & 34.00 & 82.00 & 9.06073 & 10.93927 \\
\hline 2 & 16.00 & 19.00 & 26.00 & 34.00 & 22.00 & 25.00 & 60.00 & 14.90009 & 1.09991 \\
\hline 3 & 7.00 & 20.00 & 20.00 & 33.00 & 20.00 & 27.00 & 75.00 & 5.59932 & 1.40068 \\
\hline 4 & 22.00 & 30.00 & 23.00 & 35.00 & 33.00 & 30.00 & 59.00 & 19.84132 & 2.15868 \\
\hline 5 & 45.00 & 40.00 & 39.00 & 38.00 & 50.00 & 44.00 & 50.00 & 36.54868 & 8.45132 \\
\hline 6 & 76.00 & 64.00 & 64.00 & 51.00 & 74.00 & 68.00 & 55.00 & 50.68513 & 25.31487 \\
\hline 7 & 58.00 & 50.00 & 52.00 & 43.00 & 55.00 & 50.00 & 43.00 & 45.61178 & 12.38822 \\
\hline 8 & 39.00 & 44.00 & 48.00 & 49.00 & 43.00 & 51.00 & 39.00 & 40.95547 & -1.95547 \\
\hline 9 & 52.00 & 56.00 & 52.00 & 41.00 & 60.00 & 52.00 & 59.00 & 40.19232 & 11.80768 \\
\hline 10 & 13.00 & 21.00 & 31.00 & 26.00 & 27.00 & 24.00 & 68.00 & 15.59787 & -2.59787 \\
\hline 11 & 60.00 & 82.00 & 40.00 & 53.00 & 73.00 & 76.00 & 32.00 & 59.10205 & .89795 \\
\hline 12 & 41.00 & 51.00 & 32.00 & 56.00 & 49.00 & 55.00 & 39.00 & 38.52102 & 2.47898 \\
\hline 13 & 82.00 & 77.00 & 74.00 & 64.00 & 81.00 & 86.00 & 26.00 & 71.58195 & 10.41805 \\
\hline 14 & 66.00 & 79.00 & 79.00 & 78.00 & 81.00 & 72.00 & 34.00 & 62.57330 & 3.42670 \\
\hline 15 & 9.00 & 20.00 & 18.00 & 31.00 & 17.00 & 19.00 & 76.00 & 2.69965 & 6.30035 \\
\hline 16 & 73.00 & 79.00 & 76.00 & 53.00 & 66.00 & 80.00 & 40.00 & 61.76601 & 11.23399 \\
\hline 17 & 5.00 & 15.00 & 30.00 & 30.00 & 20.00 & 17.00 & 68.00 & 10.27415 & -5.27415 \\
\hline 18 & 100.00 & 76.00 & 76.00 & 67.00 & 83.00 & 88.00 & 17.00 & 76.95034 & 23.04966 \\
\hline 19 & 40.00 & 34.00 & 40.00 & 53.00 & 38.00 & 45.00 & 42.00 & 32.85686 & 7.14314 \\
\hline 20 & 58.00 & 60.00 & 50.00 & 43.00 & 50.00 & 62.00 & 31.00 & 52.81252 & 5.18748 \\
\hline 21 & 36.00 & 41.00 & 42.00 & 25.00 & 41.00 & 34.00 & 57.00 & 32.33830 & 3.66170 \\
\hline 22 & 42.00 & 42.00 & 34.00 & 34.00 & 38.00 & 38.00 & 60.00 & 26.29909 & 15.70091 \\
\hline 23 & 10.00 & 23.00 & 31.00 & 40.00 & 24.00 & 21.00 & 62.00 & 13.75501 & -3.75501 \\
\hline ta Chapter & 6 Table 1 Data.sa & ivataSet1] - I & BM SPSS Statist & stics Data Editor & & & & & \\
\hline Eile Edit & View Data & Iransform & Analyze $\subseteq$ & Graphs UUtilitie & $s$ Extensions & is Window & Help & & \\
\hline$E$ & 晋 & 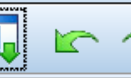 & 㨘 & \$洫 & 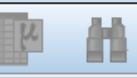 & 雷曲 & $\begin{array}{r}\Delta \sqrt{\Delta} \\
1 \text { ( }\end{array}$ & + & \\
\hline & \& Productiv & Jobsatis & $\$$ Persist & Optimism & Selfdisc & Motivate & $\$$ Procrast & \& PRE_1 & \& RES_1 \\
\hline 24 & 50.00 & 55.00 & 44.00 & 45.00 & 63.00 & 53.00 & 44.00 & 46.19281 & 3.80719 \\
\hline 25 & 44.00 & 26.00 & 31.00 & 52.00 & 54.00 & 39.00 & 45.00 & 32.83001 & 11.16999 \\
\hline 26 & 36.00 & 21.00 & 39.00 & 37.00 & 32.00 & 41.00 & 63.00 & 21.96931 & 14.03069 \\
\hline 27 & 15.00 & 29.00 & 38.00 & 32.00 & 25.00 & 23.00 & 74.00 & 12.39781 & 2.60219 \\
\hline 28 & 47.00 & 60.00 & 50.00 & 56.00 & 23.00 & 35.00 & 45.00 & 28.40255 & 18.59745 \\
\hline 29 & 25.00 & 28.00 & 16.00 & 19.00 & 24.00 & 27.00 & 68.00 & 13.95059 & 11.04941 \\
\hline 30 & 89.00 & 69.00 & 73.00 & 68.00 & 82.00 & 88.00 & 23.00 & 71.89186 & 17.10814 \\
\hline 31 & 50.00 & 62.00 & 74.00 & 48.00 & 57.00 & 59.00 & 31.00 & 59.21109 & -9.21109 \\
\hline 32 & 46.00 & 60.00 & 72.00 & 45.00 & 55.00 & 58.00 & 39.00 & 54.29807 & -8.29807 \\
\hline 33 & 78.00 & 69.00 & 82.00 & 74.00 & 84.00 & 88.00 & 36.00 & 66.29922 & 11.70078 \\
\hline 34 & 85.00 & 72.00 & 65.00 & 70.00 & 69.00 & 85.00 & 30.00 & 61.22766 & 23.77234 \\
\hline 35 & 35.00 & 40.00 & 42.00 & 45.00 & 66.00 & 41.00 & 64.00 & 32.74100 & 2.25900 \\
\hline 36 & 102.00 & 75.00 & 76.00 & 84.00 & 83.00 & 89.00 & 24.00 & 68.91743 & 33.08257 \\
\hline 37 & 66.00 & 70.00 & 74.00 & 86.00 & 80.00 & 62.00 & 31.00 & 57.98503 & 8.01497 \\
\hline 38 & 36.00 & 25.00 & 39.00 & 40.00 & 51.00 & 52.00 & 74.00 & 23.88575 & 12.11425 \\
\hline 39 & 16.00 & 29.00 & 30.00 & 34.00 & 26.00 & 34.00 & 74.00 & 12.24253 & 3.75747 \\
\hline 40 & 28.00 & 34.00 & 33.00 & 36.00 & 38.00 & 31.00 & 70.00 & 18.34105 & 9.65895 \\
\hline 41 & 17.00 & 45.00 & 30.00 & 27.00 & 27.00 & 35.00 & 67.00 & 19.60283 & -2.60283 \\
\hline 42 & 40.00 & 46.00 & 38.00 & 34.00 & 30.00 & 32.00 & 40.00 & 34.45639 & 5.54361 \\
\hline 43 & 11.00 & 27.00 & 44.00 & 54.00 & 21.00 & 49.00 & 83.00 & 6.55181 & 4.44819 \\
\hline 44 & 52.00 & 76.00 & 50.00 & 46.00 & 62.00 & 54.00 & 21.00 & 61.11034 & -9.11034 \\
\hline 45 & 27.00 & 16.00 & 34.00 & 24.00 & 37.00 & 37.00 & 45.00 & 34.13506 & -7.13506 \\
\hline 46 & 33.00 & 40.00 & 35.00 & 37.00 & 43.00 & 39.00 & 36.00 & 40.04425 & -7.04425 \\
\hline
\end{tabular}


th Chapter 16 Table 1 Data.sav [DataSet1] - IBM SPSS Statistics Data Editor

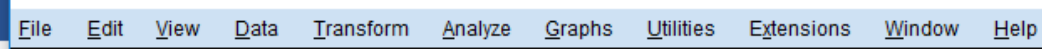

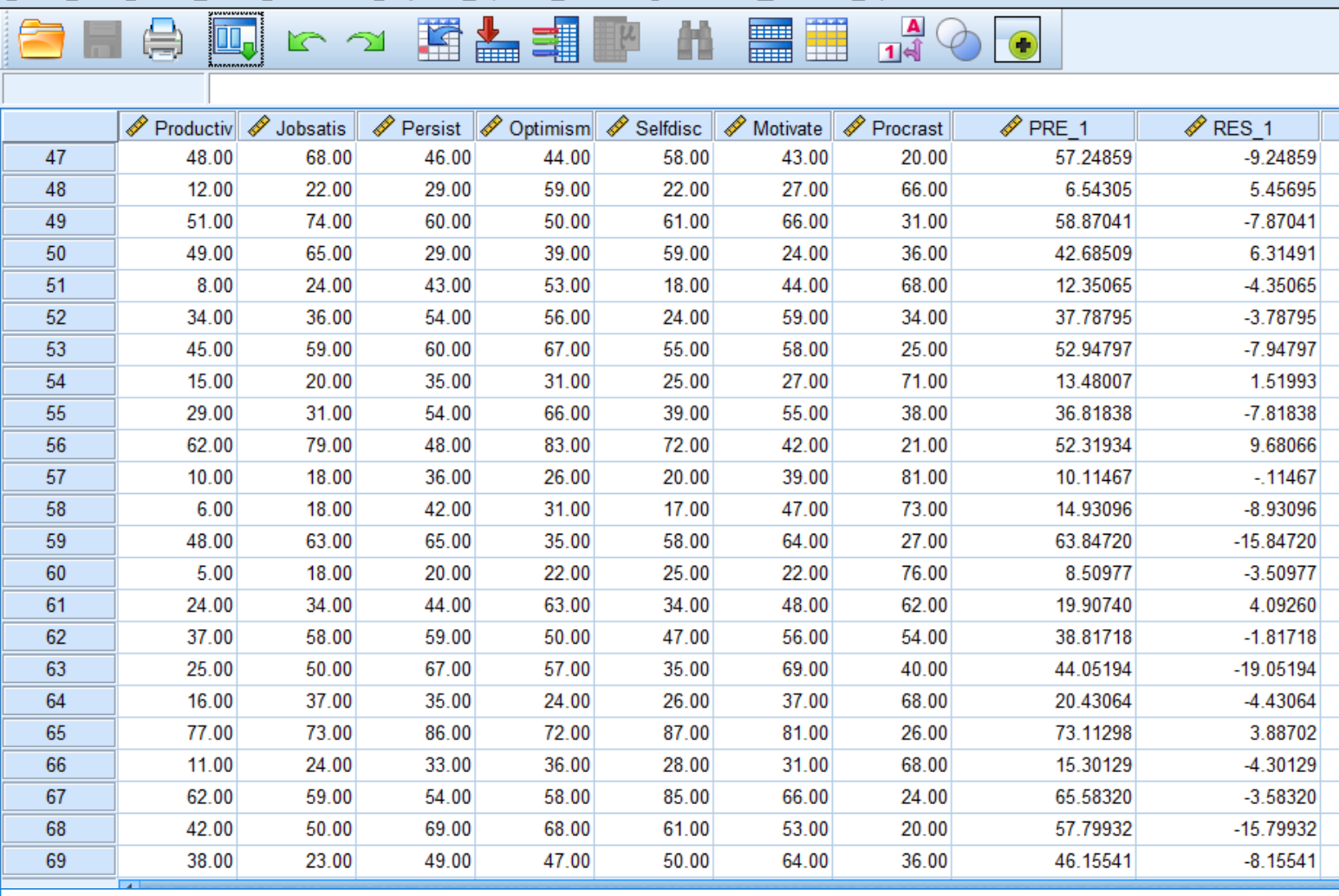

ta Chapter 16 Table 1 Data.sav [DataSet1] - IBM SPSS Statistics Data Editor

Eile É

\begin{tabular}{|c|c|c|c|c|c|c|c|c|c|}
\hline File Edit & View Data & Iransform & Annalyze & Graphs U Utilitie & Extensior & Window & Help & & \\
\hline$E$ & 恶 & 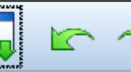 & 娄 & 占曲費 & ㅂ. & 䨐曲 & 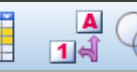 & + & \\
\hline & \& Productiv & Jobsatis & \& Persist & B Optimism & \& Selfdisc & \& Motivate & \& Procrast & \& PRE 1 & \& RES 1 \\
\hline 70 & 18.00 & 32.00 & 40.00 & 34.00 & 37.00 & 52.00 & 71.00 & 23.30063 & -5.30063 \\
\hline 71 & 49.00 & 61.00 & 52.00 & 57.00 & 65.00 & 31.00 & 28.00 & 50.62852 & -1.62852 \\
\hline 72 & 18.00 & 34.00 & 33.00 & 63.00 & 28.00 & 54.00 & 66.00 & 14.26542 & 3.73458 \\
\hline 73 & 38.00 & 34.00 & 58.00 & 66.00 & 54.00 & 49.00 & 37.00 & 42.37164 & -4.37164 \\
\hline 74 & 42.00 & 57.00 & 58.00 & 65.00 & 75.00 & 28.00 & 34.00 & 49.21070 & -7.21070 \\
\hline 75 & 21.00 & 35.00 & 43.00 & 61.00 & 30.00 & 48.00 & 78.00 & 10.53803 & 10.46197 \\
\hline 76 & 30.00 & 33.00 & 54.00 & 72.00 & 51.00 & 42.00 & 40.00 & 35.94144 & -5.94144 \\
\hline 77 & 65.00 & 82.00 & 51.00 & 86.00 & 77.00 & 59.00 & 27.00 & 54.02747 & 10.97253 \\
\hline 78 & 18.00 & 40.00 & 32.00 & 60.00 & 30.00 & 37.00 & 64.00 & 13.96531 & 4.03469 \\
\hline 79 & 44.00 & 60.00 & 59.00 & 58.00 & 50.00 & 55.00 & 36.00 & 47.17773 & -3.17773 \\
\hline 80 & 38.00 & 58.00 & 60.00 & 63.00 & 49.00 & 54.00 & 30.00 & 48.60255 & -10.60255 \\
\hline 81 & 21.00 & 38.00 & 35.00 & 42.00 & 32.00 & 37.00 & 64.00 & 19.87510 & 1.12490 \\
\hline 82 & 9.00 & 26.00 & 26.00 & 44.00 & 21.00 & 26.00 & 78.00 & 3.24256 & 5.75744 \\
\hline 83 & 23.00 & 40.00 & 50.00 & 57.00 & 28.00 & 32.00 & 72.00 & 13.33149 & 9.66851 \\
\hline 84 & 10.00 & 21.00 & 23.00 & 65.00 & 20.00 & 25.00 & 70.00 & .32556 & 9.67444 \\
\hline 85 & 95.00 & 86.00 & 87.00 & 52.00 & 76.00 & 71.00 & 42.00 & 65.85780 & 29.14220 \\
\hline 86 & 11.00 & 24.00 & 32.00 & 39.00 & 21.00 & 26.00 & 83.00 & 3.19529 & 7.80471 \\
\hline 87 & 87.00 & 93.00 & 77.00 & 58.00 & 88.00 & 82.00 & 26.00 & 76.77432 & 10.22568 \\
\hline 88 & 21.00 & 42.00 & 43.00 & 52.00 & 30.00 & 35.00 & 67.00 & 16.93865 & 4.06135 \\
\hline 89 & 16.00 & 30.00 & 32.00 & 41.00 & 24.00 & 29.00 & 31.00 & 32.09098 & -16.09098 \\
\hline 90 & 73.00 & 84.00 & 80.00 & 68.00 & 80.00 & 85.00 & 40.00 & 64.68933 & 8.31067 \\
\hline 91 & 88.00 & 88.00 & 94.00 & 43.00 & 89.00 & 93.00 & 28.00 & 85.62374 & 2.37626 \\
\hline 92 & 35.00 & 60.00 & 56.00 & 55.00 & 51.00 & 56.00 & 40.00 & 45.63419 & -10.63419 \\
\hline
\end{tabular}


由 Chapter 16 Table 1 Data.sav [DataSet1] - IBM SPSS Statistics Data Editor

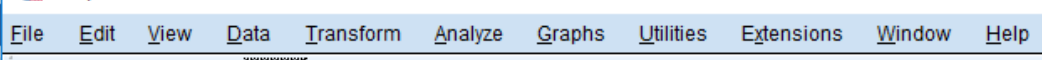

E

\begin{tabular}{|c|c|c|c|c|c|c|c|c|c|}
\hline & $\&$ Productiv & \& Jobsatis & $\&$ Persist & $\&$ Optimism & $\&$ Selfdisc & Motivate & $\&$ Procrast & $\&$ PRE_ 1 & $\&$ RES_1 \\
\hline 93 & 24.00 & 60.00 & 38.00 & 62.00 & 32.00 & 37.00 & 64.00 & 17.21616 & 6.78384 \\
\hline 94 & 31.00 & 60.00 & 42.00 & 36.00 & 48.00 & 53.00 & 45.00 & 43.06605 & -12.06605 \\
\hline 96 & 103.00 & 78.00 & 91.00 & 70.00 & 96.00 & 97.00 & 33.00 & 77.37380 & 25.62620 \\
\hline 97 & 52.00 & 55.00 & 72.00 & 48.00 & 70.00 & 75.00 & 25.00 & 68.40857 & -16.40857 \\
\hline 98 & 27.00 & 30.00 & 40.00 & 46.00 & 33.00 & 38.00 & 59.00 & 22.50834 & 4.49166 \\
\hline 100 & 24.00 & 59.00 & 32.00 & 29.00 & 35.00 & 40.00 & 57.00 & 29.50649 & -5.50649 \\
\hline 101 & 18.00 & 53.00 & 23.00 & 28.00 & 28.00 & 20.00 & 73.00 & 12.79399 & 5.20601 \\
\hline 102 & 34.00 & 44.00 & 66.00 & 56.00 & 42.00 & 47.00 & 54.00 & 34.52636 & -.52636 \\
\hline 103 & 43.00 & 52.00 & 68.00 & 63.00 & 61.00 & 67.00 & 36.00 & 53.11125 & -10.11125 \\
\hline 104 & 55.00 & 55.00 & 79.00 & 78.00 & 66.00 & 55.00 & 39.00 & 49.99593 & 5.00407 \\
\hline 109 & 20.00 & 31.00 & 33.00 & 75.00 & 30.00 & 35.00 & 80.00 & .74645 & 19.25355 \\
\hline 110 & 90.00 & 83.00 & 84.00 & 50.00 & 73.00 & 70.00 & 39.00 & 65.82911 & 24.17089 \\
\hline 111 & 21.00 & 34.00 & 42.00 & 39.00 & 20.00 & 25.00 & 81.00 & 6.99526 & 14.00474 \\
\hline 112 & 89.00 & 95.00 & 97.00 & 61.00 & 98.00 & 84.00 & 23.00 & 86.18421 & 2.81579 \\
\hline 113 & 24.00 & 46.00 & 46.00 & 54.00 & 33.00 & 35.00 & 66.00 & 18.97938 & 5.02062 \\
\hline 114 & 18.00 & 32.00 & 34.00 & 43.00 & 34.00 & 30.00 & 36.00 & 33.02069 & -15.02069 \\
\hline 115 & 74.00 & 87.00 & 88.00 & 70.00 & 84.00 & 88.00 & 32.00 & 72.40619 & 1.59381 \\
\hline
\end{tabular}

由. Chapter 16 Table 1 Data.sav [DataSet1] - IBM SPSS Statistics Data Editor

File Edit View Data Iransform Analyze Graphs Utilities Extensions Window $\underline{H}$ elp

\begin{tabular}{|c|c|c|c|c|c|c|c|c|c|}
\hline & \& Productiv & \& Jobsatis & $\&$ Persist & A Optimism & $\not$ Selfdisc & $\&$ Motivate & \& Procrast & \& PRE 1 & \& RES 1 \\
\hline 116 & 98.00 & 82.00 & 91.00 & 37.00 & 83.00 & 90.00 & 25.00 & 85.05292 & 12.94708 \\
\hline 117 & 38.00 & 62.00 & 57.00 & 59.00 & 55.00 & 58.00 & 42.00 & 45.60597 & -7.60597 \\
\hline 118 & 34.00 & 71.00 & 49.00 & 71.00 & 42.00 & 52.00 & 61.00 & 25.97045 & 8.02955 \\
\hline 119 & 29.00 & 58.00 & 40.00 & 34.00 & 48.00 & 61.00 & 62.00 & 35.41519 & -6.41519 \\
\hline 120 & 44.00 & 28.00 & 63.00 & 59.00 & 57.00 & 62.00 & 35.00 & 49.26827 & -5.26827 \\
\hline 121 & 93.00 & 68.00 & 83.00 & 62.00 & 86.00 & 84.00 & 23.00 & 76.37536 & 16.62464 \\
\hline 122 & 62.00 & 65.00 & 82.00 & 58.00 & 81.00 & 82.00 & 20.00 & 76.52116 & -14.52116 \\
\hline 123 & 25.00 & 32.00 & 44.00 & 41.00 & 43.00 & 58.00 & 51.00 & 36.00760 & -11.00760 \\
\hline 124 & 61.00 & 35.00 & 71.00 & 67.00 & 69.00 & 74.00 & 37.00 & 54.70334 & 6.29666 \\
\hline 125 & 22.00 & 57.00 & 31.00 & 26.00 & 38.00 & 42.00 & 62.00 & 28.58246 & -6.58246 \\
\hline 126 & 29.00 & 56.00 & 43.00 & 38.00 & 32.00 & 34.00 & 69.00 & 21.18442 & 7.81558 \\
\hline 127 & 44.00 & 46.00 & 61.00 & 65.00 & 37.00 & 53.00 & 29.00 & 43.75685 & 24315 \\
\hline 128 & 43.00 & 42.00 & 69.00 & 73.00 & 56.00 & 74.00 & 36.00 & 49.53149 & -6.53149 \\
\hline 129 & 36.00 & 44.00 & 67.00 & 63.00 & 64.00 & 72.00 & 39.00 & 52.49380 & -16.49380 \\
\hline 130 & 55.00 & 72.00 & 77.00 & 59.00 & 77.00 & 80.00 & 32.00 & 67.65326 & -12.65326 \\
\hline 131 & 14.00 & 50.00 & 55.00 & 65.00 & 56.00 & 55.00 & 52.00 & 37.07036 & -23.07036 \\
\hline 132 & 8.00 & 48.00 & 50.00 & 80.00 & 53.00 & 49.00 & 72.00 & 19.18581 & -11.18581 \\
\hline 133 & 5.00 & 40.00 & 45.00 & 62.00 & 50.00 & 54.00 & 81.00 & 17.18778 & -12.18778 \\
\hline 134 & 10.00 & 58.00 & 52.00 & 65.00 & 54.00 & 51.00 & 67.00 & 27.74210 & -17.74210 \\
\hline 135 & 4.00 & 45.00 & 45.00 & 52.00 & 60.00 & 50.00 & 38.00 & 45.41591 & -41.41591 \\
\hline 136 & 17.00 & 53.00 & 49.00 & 55.00 & 47.00 & 53.00 & 79.00 & 20.96670 & -3.96670 \\
\hline 137 & 19.00 & 69.00 & 53.00 & 50.00 & 68.00 & 55.00 & 76.00 & 33.35646 & -14.35646 \\
\hline 138 & 40.00 & 68.00 & 64.00 & 73.00 & 66.00 & 71.00 & 49.00 & 46.36780 & -6.36780 \\
\hline
\end{tabular}


由 Chapter 16 Table 1 Data.sav [DataSet1] - IBM SPSS Statistics Data Editor

File Edit View Data Iransform Analyze Graphs UUtilities Extensions Window Help

\begin{tabular}{|c|c|c|c|c|c|c|c|c|c|}
\hline & $\&$ Productiv & $\&$ Jobsatis & $\&$ Persist & 8 Optimism & $\&$ Selfdisc & $\&$ Motivate & $\&$ Procrast & $\&$ PRE_1 & $\&$ RES_1 \\
\hline 139 & 31.00 & 80.00 & 73.00 & 65.00 & 65.00 & 64.00 & 82.00 & 32.66388 & -1.66388 \\
\hline 140 & 9.00 & 78.00 & 56.00 & 51.00 & 49.00 & 48.00 & 77.00 & 26.60135 & -17.60135 \\
\hline 141 & 12.00 & 82.00 & 52.00 & 50.00 & 53.00 & 51.00 & 74.00 & 29.65305 & -17.65305 \\
\hline 142 & 16.00 & 60.00 & 61.00 & 51.00 & 55.00 & 58.00 & 61.00 & 38.48213 & -22.48213 \\
\hline 143 & 14.00 & 65.00 & 55.00 & 52.00 & 56.00 & 50.00 & 60.00 & 36.60802 & -22.60802 \\
\hline 144 & 18.00 & 82.00 & 74.00 & 66.00 & 69.00 & 70.00 & 84.00 & 34.13670 & -16.13670 \\
\hline 145 & 40.00 & 72.00 & 68.00 & 64.00 & 66.00 & 61.00 & 63.00 & 40.84798 & -.84798 \\
\hline 146 & 42.00 & 64.00 & 60.00 & 53.00 & 72.00 & 49.00 & 50.00 & 47.77203 & -5.77203 \\
\hline 147 & 40.00 & 50.00 & 64.00 & 50.00 & 44.00 & 44.00 & 62.00 & 32.01017 & 7.98983 \\
\hline 148 & 19.00 & 41.00 & 60.00 & 40.00 & 29.00 & 37.00 & 77.00 & 18.85779 & .14221 \\
\hline 149 & 43.00 & 40.00 & 58.00 & 60.00 & 39.00 & 39.00 & 50.00 & 30.91089 & 12.08911 \\
\hline 150 & 16.00 & 56.00 & 74.00 & 58.00 & 27.00 & 42.00 & 83.00 & 15.87566 & .12434 \\
\hline 151 & 56.00 & 66.00 & 40.00 & 40.00 & 68.00 & 56.00 & 61.00 & 40.66168 & 15.33832 \\
\hline 152 & 34.00 & 52.00 & 64.00 & 29.00 & 32.00 & 55.00 & 85.00 & 23.60716 & 10.39284 \\
\hline 153 & 35.00 & 60.00 & 55.00 & 33.00 & 45.00 & 38.00 & 46.00 & 42.79399 & -7.79399 \\
\hline 154 & 45.00 & 54.00 & 76.00 & 47.00 & 56.00 & 63.00 & 72.00 & 38.07327 & 6.92673 \\
\hline 155 & 20.00 & 50.00 & 69.00 & 58.00 & 50.00 & 42.00 & 86.00 & 20.07707 & -.07707 \\
\hline 156 & 40.00 & 83.00 & 70.00 & 50.00 & 54.00 & 59.00 & 40.00 & 53.75985 & -13.75985 \\
\hline 157 & 49.00 & 54.00 & 69.00 & 30.00 & 48.00 & 54.00 & 47.00 & 49.77644 & -.77644 \\
\hline 158 & 37.00 & 70.00 & 80.00 & 68.00 & 27.00 & 68.00 & 63.00 & 31.08630 & 5.91370 \\
\hline 159 & 15.00 & 52.00 & 57.00 & 68.00 & 50.00 & 85.00 & 53.00 & 39.83707 & -24.83707 \\
\hline 160 & 7.00 & 47.00 & 52.00 & 81.00 & 55.00 & 50.00 & 75.00 & 18.57391 & -11.57391 \\
\hline 161 & 15.00 & 40.00 & 46.00 & 52.00 & 48.00 & 54.00 & 84.00 & 17.80880 & -2.80880 \\
\hline
\end{tabular}

† Chapter 16 Table 1 Data.sav [DataSet1] - IBM SPSS Statistics Data Editor

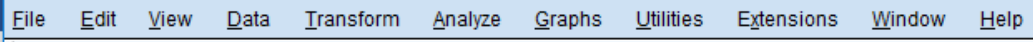
ए

\begin{tabular}{|c|c|c|c|c|c|c|c|c|c|}
\hline & \& Productiv & $\&$ Jobsatis & $\&$ Persist & $\&$ Optimism & $\&$ Selfdisc & $\&$ Motivate & $\&$ Procrast & \& PRE_1 & $\&$ RES_1 \\
\hline 162 & 11.00 & 55.00 & 55.00 & 68.00 & 59.00 & 59.00 & 77.00 & 25.22620 & -14.22620 \\
\hline 163 & 4.00 & 65.00 & 55.00 & 62.00 & 70.00 & 60.00 & 58.00 & 41.40388 & -37.40388 \\
\hline 164 & 18.00 & 50.00 & 52.00 & 51.00 & 57.00 & 59.00 & 79.00 & 26.81830 & -8.81830 \\
\hline 165 & 19.00 & 72.00 & 63.00 & 61.00 & 63.00 & 58.00 & 55.00 & 43.12441 & -24.12441 \\
\hline 166 & 40.00 & 65.00 & 67.00 & 63.00 & 60.00 & 59.00 & 55.00 & 42.18463 & -2.18463 \\
\hline 167 & 26.00 & 74.00 & 72.00 & 55.00 & 67.00 & 74.00 & 73.00 & 41.71997 & -15.71997 \\
\hline 169 & 11.00 & 85.00 & 72.00 & 51.00 & 57.00 & 39.00 & 78.00 & 31.51483 & -20.51483 \\
\hline 170 & 73.00 & 43.00 & 25.00 & 30.00 & 22.00 & 27.00 & 72.00 & 11.74636 & 61.25364 \\
\hline 171 & 28.00 & 50.00 & 28.00 & 32.00 & 35.00 & 35.00 & 57.00 & 26.10736 & 1.89264 \\
\hline 172 & 47.00 & 60.00 & 44.00 & 35.00 & 52.00 & 49.00 & 49.00 & 42.28777 & 4.71223 \\
\hline 173 & 79.00 & 84.00 & 69.00 & 48.00 & 76.00 & 72.00 & 53.00 & 56.77180 & 22.22820 \\
\hline 178 & 57.00 & 92.00 & 45.00 & 55.00 & 70.00 & 81.00 & 33.00 & 60.01631 & -3.01631 \\
\hline 179 & 38.00 & 71.00 & 37.00 & 61.00 & 52.00 & 60.00 & 40.00 & 41.44251 & -3.44251 \\
\hline 180 & 4.00 & 40.00 & 25.00 & 36.00 & 22.00 & 32.00 & 76.00 & 8.71745 & -4.71745 \\
\hline \multicolumn{10}{|l|}{181} \\
\hline \multicolumn{10}{|l|}{182} \\
\hline \multicolumn{10}{|l|}{183} \\
\hline 184 & & & & & & & & & \\
\hline
\end{tabular}

